\title{
Oxidation After Breakdown of the Chromium-Rich Scale on Stainless Steels at High Temperature: Internal Oxidation
}

\author{
T. Jonsson ${ }^{1} \cdot$ S. Karlsson ${ }^{1} \cdot$ H. Hooshyar ${ }^{1}$. \\ M. Sattari ${ }^{1}$ - J. Liske ${ }^{1}$ J.-E. Svensson ${ }^{1}$. \\ L.-G. Johansson ${ }^{1}$
}

Received: 27 October 2015/Revised: 3 January 2016/Published online: 20 January 2016

(C) The Author(s) 2016. This article is published with open access at Springerlink.com

\begin{abstract}
Breakaway oxidation of alloy $304 \mathrm{~L}$ at $600{ }^{\circ} \mathrm{C}$ was studied in four environments $\left(\mathrm{O}_{2}+\mathrm{H}_{2} \mathrm{O}+\mathrm{KCl}, \mathrm{O}_{2}+\mathrm{H}_{2} \mathrm{O}+\mathrm{SO}_{2}+\mathrm{KCl}, \mathrm{H}_{2}+\mathrm{H}_{2} \mathrm{O}+\mathrm{Ar}\right.$, $\mathrm{O}_{2}+\mathrm{K}_{2} \mathrm{CO}_{3}$ ) for up to $168 \mathrm{~h}$. The resulting scales were investigated by FIB/SEM, SEM/EDX, STEM/EELS, STEM/EDS and oxidation was elucidated by thermodynamic calculations (Thermo-Calc). The initial thin protective scale broke down in all cases. After breakaway, the scale consisted of two layers, i.e. an inward growing spinel/reaction zone and an outward growing iron-rich layer. The general features and microstructure of the scales after breakaway were similar in all environments and were explained in terms of: (1) Different diffusivities of $\mathrm{Cr}^{3+}$ and $\mathrm{Fe}^{2+}$ in the spinel oxide. (2) The appearance of a miscibility gap in the $\mathrm{FeCr}$ and $\mathrm{FeCrNi}$ spinel oxides. (3) The equilibrium composition of the spinel (at low $\mathrm{pO}_{2} \mathrm{Ni}$ is not present in the spinel).
\end{abstract}

Keywords Oxidation - Breakaway corrosion - 304L · Alkali · Water vapour · Internal oxidation $\cdot$ TEM

\section{Introduction}

Stainless steels are designed to form a dense slow-growing corundum-type $\mathrm{Cr}$-rich $\left(\left(\mathrm{Cr}_{\mathrm{x}} \mathrm{Fe}_{1-\mathrm{x}}\right)_{2} \mathrm{O}_{3}\right)$ scale in high temperature applications. In order to form such a protective scale the supply of chromium to the scale has to be sufficient. Depending on the corrosive environment and the alloy microstructure, different concentrations of $\mathrm{Cr}$ in the alloy are necessary for corrosion protection. The corundum-type $\mathrm{Cr}$ rich $\left(\left(\mathrm{Cr}_{\mathrm{x}} \mathrm{Fe}_{1-\mathrm{x}}\right)_{2} \mathrm{O}_{3}\right)$ scale is known to provide protection against oxidation and

T. Jonsson

tj@chalmers.se

1 Environmental Inorganic Chemistry, Department of Chemistry and Chemical Engineering,

Chalmers University of Technology, 41296 Göteborg, Sweden 
corrosion. A great number of publications concerning the oxidation properties of steels and stainless steels are summarized by Kofstad [1], Birks and Meier [2] and Young [3].

In demanding high temperature applications the $\left(\left(\mathrm{Cr}_{\mathrm{x}} \mathrm{Fe}_{1-\mathrm{x}}\right)_{2} \mathrm{O}_{3}\right)$ scale may lose its protective properties resulting in breakaway oxidation. The rate of further oxidation then relies on the properties of the scale formed after breakaway. Breakaway oxidation of stainless steels in various environments and at different temperatures have been reported to result in a similar microstructure consisting of an outward growing Fe-rich oxide and an inward growing $\mathrm{Fe}, \mathrm{Cr}$, (Ni) spinel oxide, see e.g. [4-15]. The microstructure of the inward growing spinel scale has been shown to be complex, including both fully oxidized regions and regions of internal oxidation as reported for $\mathrm{Fe}-\mathrm{Cr}$ model alloys at 600 to $900{ }^{\circ} \mathrm{C}[4,5,11,15-17]$. A similar behavior has been reported for commercial alloys in different corrosive environments and temperatures, see e.g. [9, 11, 16]. Different authors have attributed this characteristic breakaway behavior to a variety of causes, which are more or less specific for the type of environments studied. However, the similarities in the scale structures observed after breakaway hints that there is an underlying mechanism which is generally applicable and that does not require a specific combination of corrosive factors. The present study is designed to study that underlying mechanism using different corrosive factors to trigger breakaway oxidation in $\mathrm{Fe}, \mathrm{Cr}$, (Ni) alloys. A comparative investigation of the microstructural evolution post-breakaway oxidation is therefore performed. Breakaway oxidation is induced in alloy 304L by exposure to different corrosive environments at the same temperature and then the microstructural evolution in the different environments is studied in detail. The four corrosive environments selected were:

- $\mathrm{O}_{2}+\mathrm{H}_{2} \mathrm{O}+\mathrm{KCl}$ - (high oxygen activity)

- $\mathrm{O}_{2}+\mathrm{H}_{2} \mathrm{O}+\mathrm{KCl}+\mathrm{SO}_{2}$ - (high oxygen activity)

- $\mathrm{H}_{2} \mathrm{O}+\mathrm{H}_{2}+\mathrm{Ar}$ - (low oxygen activity)

- $\mathrm{K}_{2} \mathrm{CO}_{3}+\mathrm{O}_{2}$ - (high oxygen activity)

It has been suggested that, at high oxygen activity, water vapour and alkali cause breakaway oxidation of stainless steels in a similar way. Thus, the breakdown of the initial protective oxide in the presence of water vapor/alkali was explained by the formation of chromium(VI) oxide hydroxide/alkali chromate in a reaction with the protective scale temperatures [4, 8, 18, 19]. Addition of small amounts of sulfur dioxide has been shown to prolong the incubation time for breakaway oxidation in the presence of $\mathrm{KCl}$ and to slow down scale growth after breakaway [20]. At low oxygen activities, evaporation of chromium (VI) oxide hydroxide is negligible and the accelerated oxidation of stainless steels in $\mathrm{H}_{2}+\mathrm{H}_{2} \mathrm{O}$ environment must have other causes. Various explanations have been suggested for the effect of water vapor at low oxygen activity [16, 21-23]. In addition, one environment was selected that does not include water vapor or chlorine-containing species $\left(\mathrm{K}_{2} \mathrm{CO}_{3}+\mathrm{O}_{2}\right)$. The investigation was performed on the commercial austenitic stainless steel 304L (two grades $18 \mathrm{Cr}-10 \mathrm{Ni}$ and $18 \mathrm{Cr}-8 \mathrm{Ni}$ ) in the four different environments giving rise to breakdown of the $\left(\left(\mathrm{Cr}_{\mathrm{x}} \mathrm{Fe}_{1-\mathrm{x}}\right)_{2} \mathrm{O}_{3}\right)$ scale. 
The aim of the present paper is to investigate the oxidation of the stainless steel 304L after breakdown of the protective scale. The different corrosive environments give the possibility to study the propagation after breakaway oxidation, independent of the breakdown mechanism. The work involves a detailed microstructural investigation of the oxide scales formed after breakaway in different corrosive environments as well as thermodynamic equilibrium calculations. The following characterization techniques were employed: Scanning electron microscopy coupled with energy dispersive X-ray spectroscopy (SEM/EDX) in order to acquire an overall understanding of the microstructure (in the micrometer range) with good statistics so that characteristic and representative features of the microstructure could be detected and selected for further analysis. Scanning transmission electron microscopy coupled with energy dispersive X-ray spectroscopy (STEM/EDX) was used in order to investigate the scale microstructure and its chemical composition at nanometer range resolution. Scanning transmission electron microscopy coupled with electron energy loss spectroscopy (STEM/EELS) was used to detect trace elements due to the high detection sensitivity of this technique.

\section{Experimental Procedures}

\section{Materials}

The investigated materials are the austenitic stainless steels $304 \mathrm{~L}(18 \mathrm{Cr}-10 \mathrm{Ni})$ and $(18 \mathrm{Cr}-8 \mathrm{Ni})$, see Table 1 for detailed compositions. The material was cut into coupons $\left(15 \times 15 \times 2 \mathrm{~mm}^{3}\right)$ and grinded on 320 grit $\mathrm{SiC}$ with deionized water and then polished with 9,3 , and $1 \mu \mathrm{m}$ diamond solution on a polishing cloth. The polished samples were degreased and cleaned in acetone and ethanol using an ultrasonic bath. Salt $\left(\mathrm{KCl}\right.$ or $\left.\mathrm{K}_{2} \mathrm{CO}_{3}\right)$ was applied by spraying the samples with a saturated solution of the desired salt in water, water/ethanol or acetone. The amount of salt corresponded to a potassium content of $1.35 \mu \mathrm{mol} \mathrm{K} / \mathrm{cm}^{2}\left(0.10 \mathrm{mg} / \mathrm{cm}^{2}\right.$ in the case of $\mathrm{KCl}$ ). The samples were dried with air and stored in a desiccator prior to exposure. Mass change was measured after exposure using a six decimal Sartorius $^{\mathrm{TM}}$ balance and several samples were included for every exposure time in the mass gain curve, i.e. the spread between samples gives the error bar.

\section{Oxidation Exposures}

The samples were exposed in four corrosive environments:

Table 1 Chemical composition of the two 304L grades used for the exposures (wt $\%$ )

\begin{tabular}{lllllll}
\hline Element & $\mathrm{Fe}$ & $\mathrm{Cr}$ & $\mathrm{Ni}$ & $\mathrm{Mn}$ & $\mathrm{Si}$ & $\mathrm{Mo}$ \\
\hline $18 \mathrm{Cr}-10 \mathrm{Ni}$ & Bal. & 18.5 & 10.2 & 1.41 & 0.55 & 0.49 \\
$18 \mathrm{Cr}-8 \mathrm{Ni}$ & Bal. & 18.8 & 8.10 & 1.53 & 0.31 & 0.53 \\
\hline
\end{tabular}


- $\mathrm{O}_{2}+\mathrm{H}_{2} \mathrm{O}+\mathrm{KCl}$ - (high oxygen activity)

- $\mathrm{O}_{2}+\mathrm{H}_{2} \mathrm{O}+\mathrm{KCl}+\mathrm{SO}_{2}$ - (high oxygen activity)

- $\mathrm{H}_{2} \mathrm{O}+\mathrm{H}_{2}+\mathrm{Ar}$ - (low oxygen activity)

- $\mathrm{K}_{2} \mathrm{CO}_{3}+\mathrm{O}_{2}$ - (high oxygen activity)

All exposures in high oxygen partial pressure were isothermal and performed in silica tube furnaces, see [24] for experimental setup. The triplicate samples of 304L $(18 \mathrm{Cr}-10 \mathrm{Ni})$ were mounted on a sample holder and positioned parallel to the direction of gas flow. Temperature was kept at $600{ }^{\circ} \mathrm{C}\left( \pm 1{ }^{\circ} \mathrm{C}\right)$ and the exposures lasted 1, 24, 72 or $168 \mathrm{~h}$. The exposure gas consisted of $5 \% \mathrm{O}_{2}+95 \% \mathrm{~N}_{2}$ or $5 \% \mathrm{O}_{2}+40 \% \mathrm{H}_{2} \mathrm{O}+55 \% \mathrm{~N}_{2}$ and the flow rate was $3.2 \mathrm{~cm} / \mathrm{min}$. The dry gas was humidified to the desired water concentration. Flow rates were controlled with Bios DC2 Flow Calibrators. $\mathrm{SO}_{2}$ was added directly to the furnace $20 \mathrm{~cm}$ upstream from the samples, at a temperature of about $300{ }^{\circ} \mathrm{C}$. The flow was controlled by a digital mass flow regulator, to reach a concentration of $300 \mathrm{ppm}$ of $\mathrm{SO}_{2}$, and $\mathrm{N}_{2}$ was used as a carrier gas.

The exposures performed in low oxygen partial pressure were isothermal and performed in tabular furnaces on 304L $(18 \mathrm{Cr}-8 \mathrm{Ni})$. The gas flow was set at $0.8 \mathrm{~cm} /$ min using digital mass flow regulators. An alumina tube was set in to the furnace and samples were place in a sample holder standing parallel to the flow. A peristaltic pump was calibrated precisely and used as water supplier. The exposure gas composition was $10 \% \mathrm{H}_{2}-20 \% \mathrm{H}_{2} \mathrm{O}-\mathrm{Ar}$ while the furnace was isothermally kept at $600{ }^{\circ} \mathrm{C}\left( \pm 1{ }^{\circ} \mathrm{C}\right)$ giving an oxygen activity of about $10^{-24}$. The exposures were performed for 1, 24, 72 or $168 \mathrm{~h}$. Different exposure processes were tested (using oxygen and humidity sensors) to achieve the optimum process to get rid of the impurity traces available in the environment and thus provide the intended low oxygen activity [25].

\section{X-ray Diffraction (XRD)}

Crystalline corrosion products were analyzed with grazing-incidence X-ray diffraction (GI-XRD) using a Siemens D5000 powder diffractometer, equipped with grazing incidence beam attachment and a Göbel mirror. $\mathrm{Cu} \mathrm{K} \alpha$ radiation was used and the angle of incidence was $1^{\circ}-10^{\circ}$. The measurement range was $20^{\circ}<2 \theta<70^{\circ}$.

\section{Broad Ion Beam (BIB)}

Wide cross sections in the millimeter range were prepared using two broad ion beam (BIB) instruments: a Hitachi E-3500 and a Gatan Illion system. The instruments were equipped with argon ion guns for sputtering which were operated at $6 \mathrm{kV}$ for 3-5 h. Protective masks were positioned on the top surface of the samples in order to shield them from ion beam damage as well as to render a smooth cross section. Furthermore, to enhance the surface finish and to avoid projecting the surface topography on to the final cross-section (curtaining effect), a thin glass sheet was applied to the samples' top surface using super glue adhesive. After the glue 
was cured, samples were dry cut using a low speed diamond saw before mounting in the broad ion beam (BIB) instrument.

\section{Analytical Scanning Electron Microscopy}

An FEI Quanta 200 Environmental Scanning Electron Microscope (SEM) equipped with a field emission gun (FEG) was used for analytical scanning electron microscopy. The following SEM operational conditions were employed: accelerating voltage of $10-15 \mathrm{kV}$ and $10 \mathrm{~mm}$ working distance. Both secondary electron (SE) and backscattered electron (BSE) imaging modes were used. Chemical analysis was carried out using an $80 \mathrm{~mm}^{2} \mathrm{X}-\mathrm{Max}^{\mathrm{N}}$ Oxford Instruments silicon drift detector (SDD) and Oxford Instruments INCA Energy Dispersive X-ray (EDX) software. For consistency all the EDX results are presented in atomic percentages of the total cation content.

\section{Thin Foil Specimen Preparation}

Thin foil specimens for subsequent transmission electron microscopy analysis were prepared using an in-situ lift-out technique [26] in an FEI Strata 235 DualBeam and an FEI Versa 3D DualBeam focused ion beam/scanning electron microscope (FIB/ SEM) instruments both equipped with OmniProbe micromanipulators. Thin crosssectional specimens were extracted from the samples using the micromanipulator and then welded onto a copper grid for further ion milling. The samples were first investigated with top view SEM imaging using the SEM column of the FIB/SEM to locate region of interest. Then a $2 \mu \mathrm{m}$ wide and $4 \mu \mathrm{m}$ thick platinum strip was deposited on the area of interest; first, a $100 \mathrm{~nm}$ thick protective layer of platinum was deposited using electron beam, and then this strip was thickened to $4 \mu \mathrm{m}$ with ion-assisted platinum deposition. This was done to prevent $\mathrm{Ga}$ ion beam damage and milling of the oxide layer during subsequent milling of the lift-out specimen. Thereafter a specimen, about $10 \mu \mathrm{m}$ in depth below the protected region, was lifted out from the sample and transferred onto a copper grid using the micromanipulator and milled down to electron transparency $(\sim 100 \mathrm{~nm})$. Finally, Ar ion milling was used to further reduce the amount of Ga ion damage from the FIB process in some of the samples employing a Fischione 1010 argon mill instrument operating at $1 \mathrm{kV}$, $3 \mathrm{~mA}$, incident angle of $6^{\circ}$ and rocking angle of $25^{\circ}$ for about $15 \mathrm{~min}$.

\section{Analytical Transmission Electron Microscopy}

The analytical scanning transmission electron microscopy (STEM) investigation was carried out using a Phillips CM200 FEG microscope and an FEI Titan 80-300 microscope equipped with a Gatan 866 GIF Tridiem energy filter. Both TEMs were equipped with Oxford Instruments Inca X-Sight energy dispersive X-ray (EDX) system, which was used for elemental mapping, linescans and chemical quantification while only the FEI Titan 80-300 was employed for electron energy loss spectroscopy (EELS) analysis on one of the samples using a Gatan 866 GIF Tridiem energy filter. The CM200 microscope was operated at $200 \mathrm{kV}$ while the FEI Titan 
80-300 was operated at $300 \mathrm{kV}$. The EELS technique was only used for qualitative identification of elements while EDX was employed for quantitative analysis. The sample with the longest exposure time after breakaway and highest oxygen activity was investigated with EELS for trace amounts of oxygen in the alloy matrix ahead of the oxidation front. Since no oxygen was detected in the alloy matrix in this sample, it was considered that the possibility of finding oxygen in other samples with shorter exposure time and lower oxygen activity was low. Hence, EELS investigation was not carried out on these samples. Due to the technical difficulties in quantifying light elements (e.g. oxygen) using EDX in thin foil specimens [27] elemental composition of the oxide scales are presented in terms of percentages of the total cation content. The diffraction patterns were indexed by direct measurement and not ratios.

\section{Thermodynamic Calculations}

Thermodynamic calculations were performed using the THERMO-CALC program $[28,29]$ with the database TCFE7. The software was used in order to calculate the equilibrium composition of the different oxide phases formed by an alloy with the 304L composition at $600{ }^{\circ} \mathrm{C}$, as a function of $\mathrm{O}_{2}$ activity.

\section{Results}

Exposures have been performed on two grades of $304 \mathrm{~L}$ steel $(18 \mathrm{Cr}-10 \mathrm{Ni}$ and $18 \mathrm{Cr}-$ $8 \mathrm{Ni}$ ) in four corrosive environments:

- $\mathrm{O}_{2}+\mathrm{H}_{2} \mathrm{O}+\mathrm{KCl}$ (high oxygen activity) - Alloy $18 \mathrm{Cr}-10 \mathrm{Ni}$

- $\mathrm{O}_{2}+\mathrm{H}_{2} \mathrm{O}+\mathrm{KCl}+\mathrm{SO}_{2}$ (high oxygen activity) - Alloy $18 \mathrm{Cr}-10 \mathrm{Ni}$

- $\mathrm{H}_{2} \mathrm{O}+\mathrm{H}_{2}+\mathrm{Ar}$ (low oxygen activity) - Alloy $18 \mathrm{Cr}-8 \mathrm{Ni}$

- $\mathrm{K}_{2} \mathrm{CO}_{3}+\mathrm{O}_{2}$ (high oxygen activity) - Alloy $18 \mathrm{Cr}-10 \mathrm{Ni}$

Table 2 Summary of the incubation time before breakdown of the protective scale, growth rate after break and the dominating breakdown mechanisms of $304 \mathrm{~L}$ at $600{ }^{\circ} \mathrm{C}$ in the different environments. The incubation time is an interpretation of the plan view images since the localized behavior makes it impossible to use the mass gain data

\begin{tabular}{llll}
\hline Environment & Incubation time $(\mathrm{h})$ & Growth rate after break & Breakdown mechanism \\
\hline Dry $\mathrm{O}_{2} *$ & - & - & - \\
$\mathrm{O}_{2}+\mathrm{H}_{2} \mathrm{O}^{*}$ & $\approx 24$ & Fast & $\mathrm{CrO}_{2}(\mathrm{OH})_{2}$ \\
$\mathrm{O}_{2}+\mathrm{H}_{2} \mathrm{O}+\mathrm{KCl}$ & $\approx 1$ & Fast & $\mathrm{K}_{2} \mathrm{CrO}_{4}$ \\
$\mathrm{O}_{2}+\mathrm{H}_{2} \mathrm{O}+\mathrm{KCl}+\mathrm{SO}_{2}$ & $\approx 24$ & Medium fast & $\mathrm{K}_{2} \mathrm{CrO}_{4}$ \\
$\mathrm{H}_{2}+\mathrm{H}_{2} \mathrm{O}+\mathrm{Ar}$ & $\approx 1$ & Very fast & $\mathrm{See} \mathrm{discussion}$ \\
$\mathrm{O}_{2}+\mathrm{K}_{2} \mathrm{CO}_{3}$ & $<24$ & Medium fast & $\mathrm{K}_{2} \mathrm{CrO}_{4}$ \\
\hline
\end{tabular}

* Data from literature [9] 
The focus of this paper is the microstructural evolution of the oxide scale after breakaway. However, the general features of the oxidation kinetics and surface morphology in the different environments are described first and summarized in Table 2.

\section{Oxidation Kinetics and Surface Morphology}

\section{Oxidation Kinetics}

Figure 1a, b shows mass gain curves for $304 \mathrm{~L}$ (both $18 \mathrm{Cr}-10 \mathrm{Ni}$ and $18 \mathrm{Cr}-8 \mathrm{Ni}$ ) exposed in different environments including dry $\mathrm{O}_{2}$ and $\mathrm{O}_{2}+40 \% \mathrm{H}_{2} \mathrm{O}$ (from [9]). The mass gains recorded in $\mathrm{O}_{2}+\mathrm{H}_{2} \mathrm{O}, \mathrm{O}_{2}+\mathrm{H}_{2} \mathrm{O}+\mathrm{KCl}, \mathrm{O}_{2}+\mathrm{H}_{2} \mathrm{O}+\mathrm{SO}_{2}+-$ $\mathrm{KCl}, \mathrm{H}_{2}+\mathrm{H}_{2} \mathrm{O}+\mathrm{Ar}, \mathrm{O}_{2}+\mathrm{K}_{2} \mathrm{CO}_{3}$ all indicate breakaway oxidation. The only environment giving a slow-growing scale is dry oxygen where a $200 \mathrm{~nm} \mathrm{Cr}$-rich
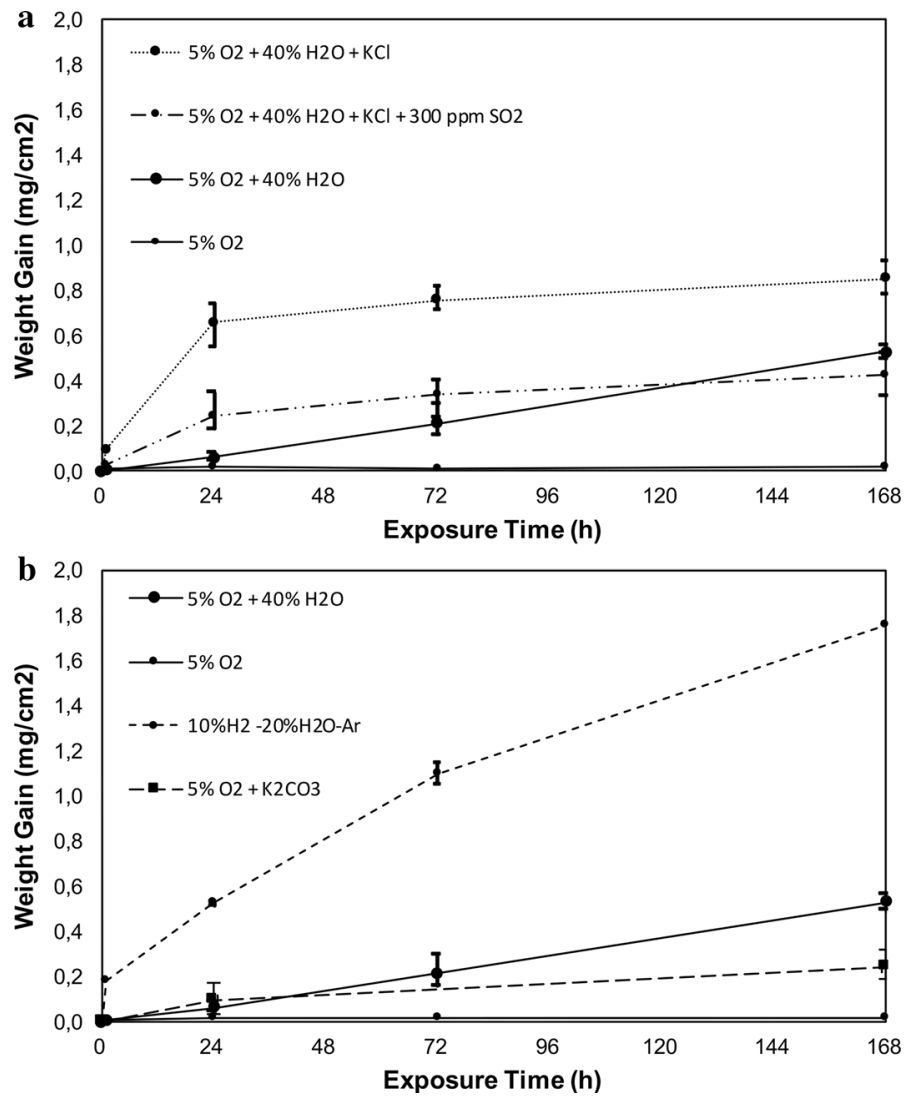

Fig. 1 a, b Mass gain of alloy $304 \mathrm{~L}(18 \mathrm{Cr}-10 \mathrm{Ni})$ in dry $\mathrm{O}_{2}$ coated with $\mathrm{K}_{2} \mathrm{CO}_{3}$, in the presence and absence of $300 \mathrm{ppm} \mathrm{SO}_{2}$ in $5 \% \mathrm{O}_{2}+40 \% \mathrm{H}_{2} \mathrm{O}+\mathrm{KCl}$ at $600{ }^{\circ} \mathrm{C}$ and from $304 \mathrm{~L} \mathrm{(18Cr-8Ni)} \mathrm{exposed} \mathrm{in}$ $10 \% \mathrm{H}_{2}-20 \% \mathrm{H}_{2} \mathrm{O}-\mathrm{Ar}$. Reference exposures in dry $5 \% \mathrm{O}_{2}$ and $5 \% \mathrm{O}_{2}+40 \% \mathrm{H}_{2} \mathrm{O}$ at $600{ }^{\circ} \mathrm{C}$ are also included from [9] 
$(\mathrm{Fe}, \mathrm{Cr})_{2} \mathrm{O}_{3}$ protective oxide was detected after $168 \mathrm{~h}$, in accordance with the minimal mass gain [9]. Both 304L grades studied behaved in the same way in dry $\mathrm{O}_{2}$ (only $18 \mathrm{Cr}-10 \mathrm{Ni}$ shown). In, contrast, exposure in $\mathrm{O}_{2}+\mathrm{H}_{2} \mathrm{O}$ environment resulted in a strongly corroded surface with island-like features [9]. With time, the oxide islands grow in size and increase in number, the oxidation kinetics during the first $168 \mathrm{~h}$ being linear. The addition of small amounts of $\mathrm{KCl}\left(\mathrm{O}_{2}+\mathrm{H}_{2} \mathrm{O}+\mathrm{KCl}\right)$ resulted in significantly faster corrosion in the initial stages. The effect of $\mathrm{KCl}$ on mass gain is initially smaller in the presence of $300 \mathrm{ppm} \mathrm{SO}_{2}$. However, $\mathrm{SO}_{2}$ has little effect on the slope of the mass gain curve between 24 and $168 \mathrm{~h}$. The mass gain curve in $\mathrm{K}_{2} \mathrm{CO}_{3}+\mathrm{O}_{2}$ also indicates breakaway oxidation. The highest mass gains after $168 \mathrm{~h}$ were recorded in $10 \% \mathrm{H}_{2}+20 \% \mathrm{H}_{2} \mathrm{O}+\mathrm{Ar}$. A comparison of all the investigated samples shows that oxidation is initially fastest in the presence of $\mathrm{KCl}$, while the $10 \% \mathrm{H}_{2}+20 \% \mathrm{H}_{2} \mathrm{O}+\mathrm{Ar}$ environment caused the fastest corrosion between 24 and $168 \mathrm{~h}$.

\section{Surface Morphology: $\mathrm{O}_{2}+\mathrm{H}_{2} \mathrm{O}+\mathrm{KCl}$}

The effect of $\mathrm{KCl}$ on the corrosion of $304 \mathrm{~L}(18-10)$ at $600{ }^{\circ} \mathrm{C}$ has been reported in several papers, see e.g. [8], and the present plan view analysis corresponds closely to previous results. Figure 2 shows BSE images of samples exposed in the presence
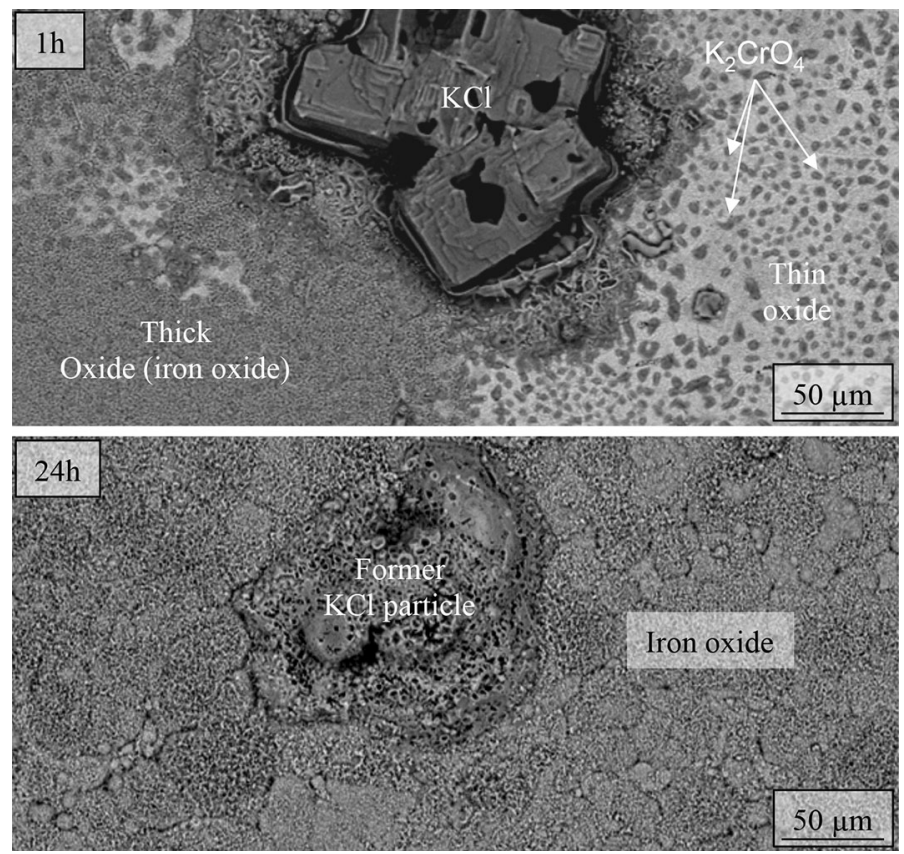

Fig. 2 BSE plan view images of 304L (18Cr-10Ni) samples exposed for 1 and $24 \mathrm{~h}$ at $600{ }^{\circ} \mathrm{C}$ in $5 \%$ $\mathrm{O}_{2}+40 \% \mathrm{H}_{2} \mathrm{O}+\mathrm{KCl}$. After $1 \mathrm{~h}$ exposure some thin protective scale with $\mathrm{K}_{2} \mathrm{CrO}_{4}$ particles could be observed together with thicker scale and unreacted $\mathrm{KCl}$. Longer exposure times gives a surface morphology consisting of iron oxide and former $\mathrm{KCl}$ particles 
of $\mathrm{KCl}$ in $5 \% \mathrm{O}_{2}+40 \% \mathrm{H}_{2} \mathrm{O}$ environment for 1 and $24 \mathrm{~h}$. After $1 \mathrm{~h}$, the partly unreacted salt particles have become surrounded by an oxide rim. Besides the salt particle, two additional morphologies are visible at this stage. The dark area (lower left) corresponds to thick oxide while the brighter area is covered by a thin oxide. The dark, 1-2 $\mu \mathrm{m}$ size, spots on the oxide surface were identified as potassium chromate $\left(\mathrm{K}_{2} \mathrm{CrO}_{4}\right)$ [8]. After $24 \mathrm{~h}$ the entire surface was covered by thick, Fe-rich scale and the former salt crystals were replaced by irregularly shaped oxide agglomerations. Between the oxide agglomerations the oxide scale exhibited an island-like morphology that reflects the substrate grain structure. According to SEM/EDX and XRD analyses the outer part of the thicker oxide consisted of almost pure hematite. The surface morphology after $168 \mathrm{~h}$ was similar (not shown).

Surface Morphology: $\mathrm{O}_{2}+\mathrm{H}_{2} \mathrm{O}+\mathrm{KCl}+\mathrm{SO}_{2}$

Figure 3 shows BSE images of samples exposed for 24 and $168 \mathrm{~h}$. SEM/EDX analysis showed that the small $(<10 \mu \mathrm{m}) \mathrm{KCl}$ particles were fully converted to potassium sulphate $\left(\mathrm{K}_{2} \mathrm{SO}_{4}\right)$ after $24 \mathrm{~h}$. The larger $\mathrm{KCl}$ particles were only partly converted after $24 \mathrm{~h}$ as shown by the detection of chlorine. In contrast to the corresponding exposure in the absence of $\mathrm{SO}_{2}$, large parts of the surface were still covered by thin oxide after $24 \mathrm{~h}$, in agreement with the relatively low mass gain
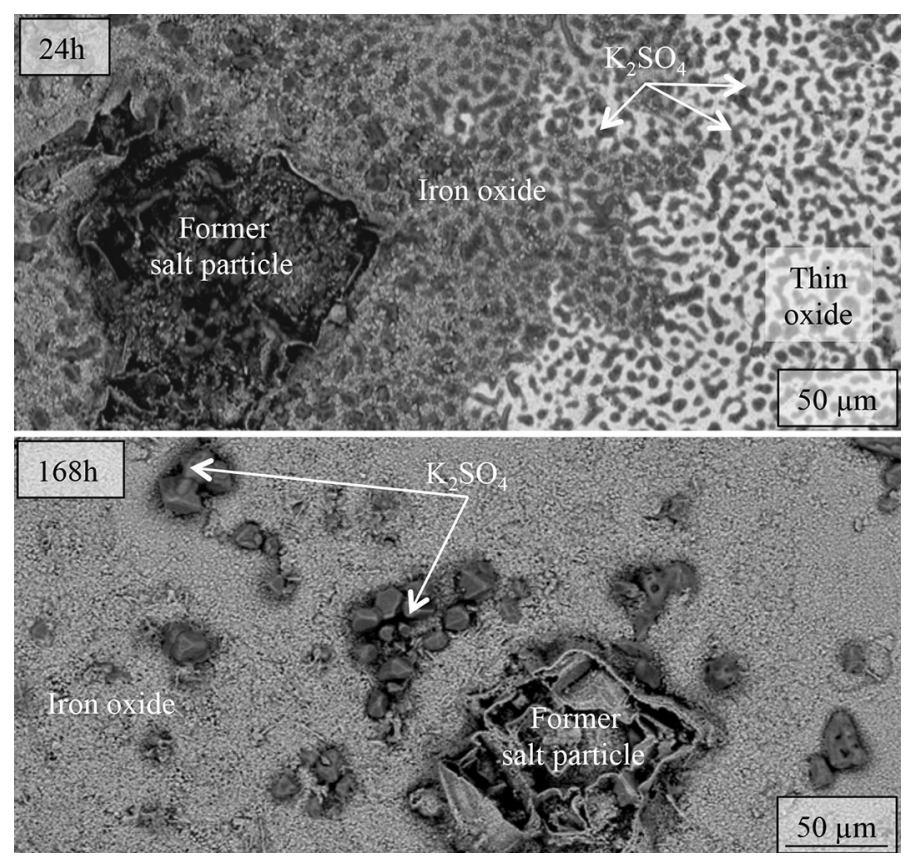

Fig. 3 BSE plan view images of $304 \mathrm{~L}(18 \mathrm{Cr}-10 \mathrm{Ni})$ samples exposed for 1,24 and $168 \mathrm{~h}$ at $600{ }^{\circ} \mathrm{C}$ in $5 \%$ $\mathrm{O}_{2}+40 \% \mathrm{H}_{2} \mathrm{O}+300 \mathrm{ppm} \mathrm{SO} \mathrm{SO}_{2} \mathrm{KCl}$. After $24 \mathrm{~h}$ exposure most of the surface is covered by a thicker iron rich oxide while only some regions with thin scale could be observed. Longer exposure times gives a surface morphology consisting of iron oxide and former $\mathrm{KCl}$ particles 
(Fig. 1a). According to SEM/EDX and XRD analyses, the outer part of the thick oxide consisted of almost pure hematite while the thin oxide was chromium-rich. After $168 \mathrm{~h}$ the $\mathrm{KCl}$ was completely reacted, no chlorine being detected, the former salt particles consisting of a $\mathrm{K}_{2} \mathrm{SO}_{4}$-rich centre surrounded by a Fe-rich oxide rim $(\mathrm{SEM} / \mathrm{EDX})$. In the vicinity of the former $\mathrm{KCl}$ particles, dark 2-8 $\mu \mathrm{m}$ diameter $\mathrm{K}_{2} \mathrm{SO}_{4}$ particles appeared. After $168 \mathrm{~h}$ the entire surface was covered by a uniform thick Fe-rich oxide scale (hematite according to XRD and SEM/EDX) containing large $\mathrm{K}_{2} \mathrm{SO}_{4}$ particles, see Fig. 3 .

Surface Morphology: $\mathrm{H}_{2} \mathrm{O}+\mathrm{H}_{2}+\mathrm{Ar}$

Figure 4 shows BSE images of samples exposed in $10 \% \mathrm{H}_{2}+20 \% \mathrm{H}_{2} \mathrm{O}+\mathrm{Ar}$ for 1 and $24 \mathrm{~h}$. After $1 \mathrm{~h}$ most of the surface is covered by thick scale. However, there are small "islands" covered by thin oxide in the scale. The size of the regions covered
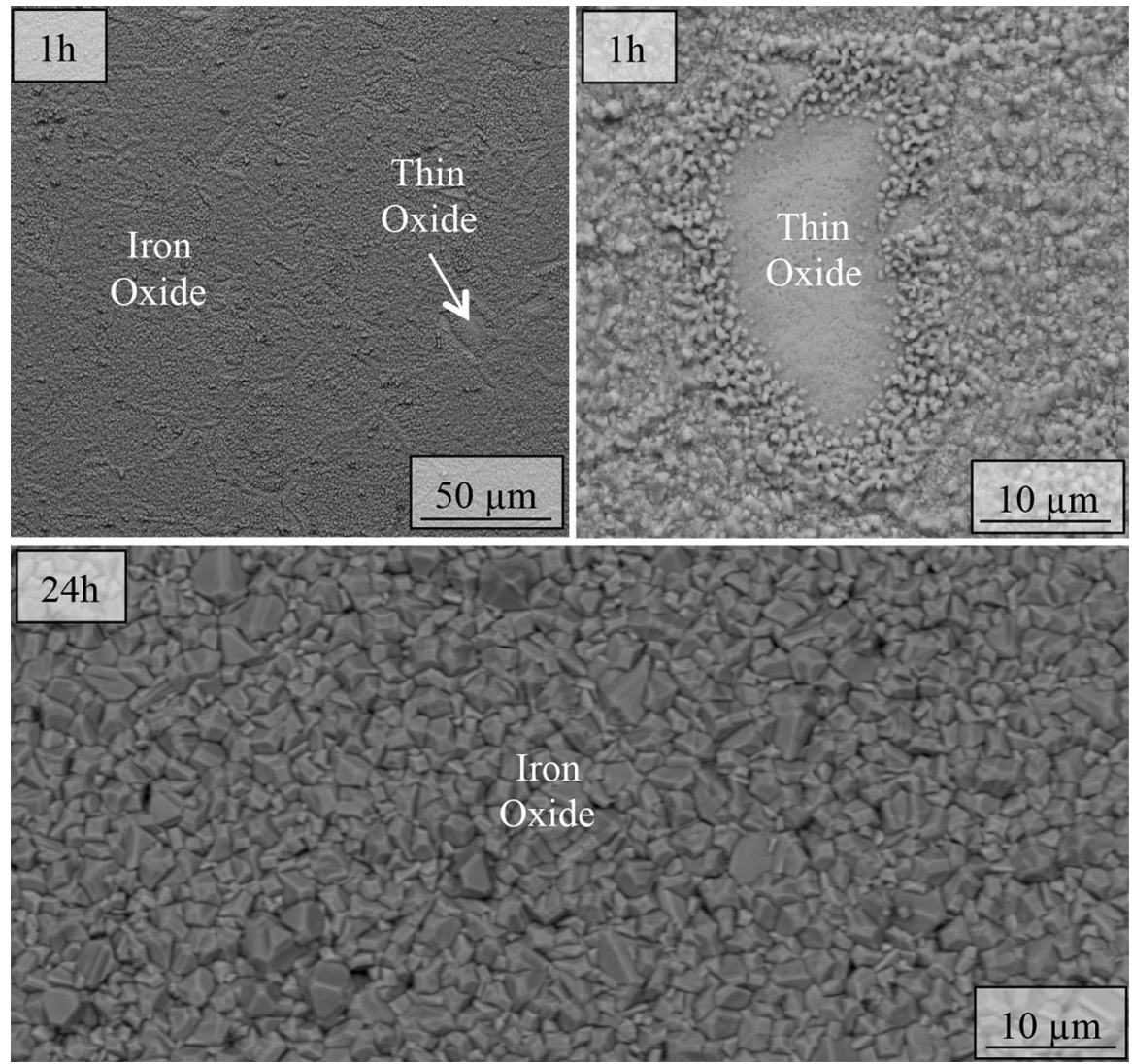

Fig. 4 BSE plan view of the $304 \mathrm{~L}(18 \mathrm{Cr}-8 \mathrm{Ni})$ samples exposed at $600{ }^{\circ} \mathrm{C}$ in the environment containing $10 \% \mathrm{H}_{2}-20 \% \mathrm{H}_{2} \mathrm{O}-$ Ar. After $1 \mathrm{~h}$ exposure thin protective scale could be observed on small regions together with thicker scale iron rich scale. Longer exposure times gives a surface morphology consisting of iron oxide 
by thin oxide corresponds to the typical alloy grain size. At this stage the scale morphology on the alloy grains was different from that at the alloy grain boundaries (Fig. 4). After 24 and $168 \mathrm{~h}$ the entire surface was covered by magnetite (SEM/ EDX and XRD). The grain size of the surface oxide had grown compared to $1 \mathrm{~h}$ 's exposure.

\section{Microstructural Evolution After Breakaway}

According to the oxidation kinetics and the examination of the surface morphology, the thin protective scale suffered breakdown in all environments studied except dry $\mathrm{O}_{2}$. However, the incubation time to breakaway differed (Table 2). While the breakdown was initially local in all cases, with time the entire surface became covered by thick rapidly growing scale.

\section{$\mathrm{O}_{2}+\mathrm{H}_{2} \mathrm{O}+\mathrm{KCl}$}

After $1 \mathrm{~h}$, two distinctive scale morphologies were observed (Fig. 2). Previously it was shown that the thick oxide developed under these exposure conditions consists of a 1-2 $\mu \mathrm{m}$ thick duplex oxide scale [8], the outer oxide layer being made up of almost pure hematite while the inward growing oxide consists of spinel-type oxide with a typical composition of $40 \mathrm{wt} \% \mathrm{Fe}, 40 \mathrm{wt} \% \mathrm{Cr}$ and $20 \mathrm{wt} \% \mathrm{Ni}$, (cationic) i.e. $(\mathrm{Fe}, \mathrm{Cr}, \mathrm{Ni})_{3} \mathrm{O}_{4}$. It was reported that the thin oxide consists of an approximately $100 \mathrm{~nm}$ Cr-rich oxide [8]. After $24 \mathrm{~h}$ the entire surface was covered by thick oxide scale (not shown). The present results show that the oxide formed after $24 \mathrm{~h}$ was similar to the thick oxide observed after $1 \mathrm{~h}$. Previously it was shown that the outer part of the scale consists of almost pure hematite while the inner part consists of FeCrNi spinel [8].

Figure 5a shows a BSE image of a BIB cross-section trough the scale after $168 \mathrm{~h}$. Similar to the situation after $24 \mathrm{~h}$ [8], the scale is layered, consisting of an outward growing and an inward- growing part. There is a characteristic variation in scale thickness, from about $3 \mu \mathrm{m}$ at the alloy grain boundaries to about $10 \mu \mathrm{m}$ at the grain centers. The thicker scale corresponds to island-like features in the outward-grown scale and craterlike features in the inward-grown scale. The outward-grown scale consisted of hematite (SEM/EDX and XRD). The inward-growing oxide exhibited two distinct microstructures; see below. Figure 5b shows a BSE image at higher magnification of the region indicated in Fig. 5a. This morphology was observed on about $10 \%$ of the inward-growing scale (interpreting SEM/BSE and SEM/EDX from the several mm wide BIB cross-section) after $168 \mathrm{~h}$ and consists of small dark regions (labeled "oxide" in Fig. 5b) surrounded by brighter regions, (labeled "reaction zone"). The dark regions have an oxygen content of 55-60 at.\% while the reaction zone has an oxygen content of 30-40 at.\% (SEM/EDX, the iron oxide in the upper part of the scale was used as a standard for the quantification of oxygen). It may be noted that the overall composition of the inward-growing part of the scale in Fig. 5b, with about $40 \% \mathrm{Fe}, 30 \% \mathrm{Cr}$ and $20 \% \mathrm{Ni}$ (cations), is iron-deficient compared to the alloy. A TEM sample was ion milled from a region similar to the area labeled " $5 c$ " in Fig. 5b, using the FIB/SEM, showing the reaction zone and the 

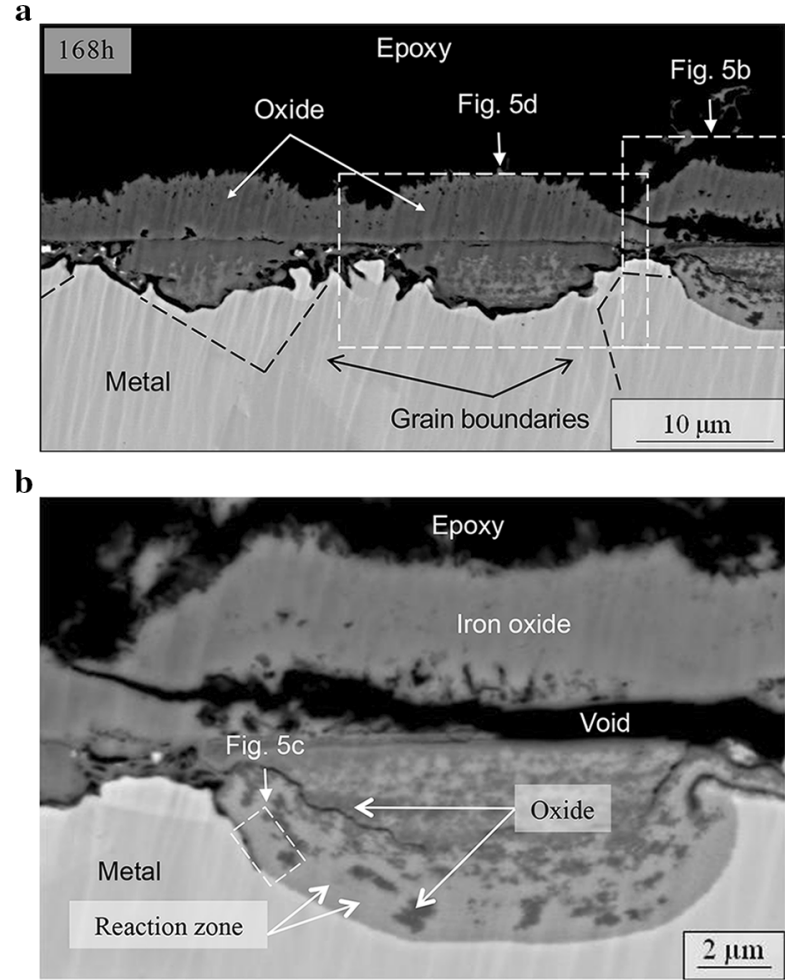

Fig. 5 a BSE image of a BIB cross-section through the oxide scale and into the alloy on the $304 \mathrm{~L}(18 \mathrm{Cr}-$ $10 \mathrm{Ni}$ ) samples exposed for $168 \mathrm{~h}$ at $600{ }^{\circ} \mathrm{C}$ in $5 \% \mathrm{O}_{2}+40 \% \mathrm{H}_{2} \mathrm{O}+\mathrm{KCl}$. A magnified image of the marked region close to the right hand side of the micrograph is shown in (b) and the SEM/EDX elemental maps from the central marked region is shown in (d). b BSE image of the marked area in (a). The inward growing oxide scale can be divided into darker areas (fully oxidized regions) and brighter areas, i.e. mixed oxide and metal (reaction zone). A TEM sample was taken from a similar region as indicated in the marked region. c HAADF image of a region similar to the marked region in (b). The inward growing oxide scale can be divided into a region of mixed oxide and metal, i.e. a reaction zone, and darker fully oxidized regions. At the alloy grain boundary a $\mathrm{Fe}-\mathrm{Cr}$ oxide could be found. CBED patterns from the oxides are inseted in the image. The oxide at the grain boundary was indexed as a spinel structure $\left(\mathrm{M}_{3} \mathrm{O}_{4}\right)$ with the zone axis [001] (i). The small oxide precipitates were also indexed as a spinel structure $\left(\mathrm{M}_{3} \mathrm{O}_{4}\right)$ with the zone axis [001] (ii). d SEM/EDX elemental maps from the marked area in (a) of the sample exposed for $168 \mathrm{~h}$ in $5 \% \mathrm{O}_{2}+40 \% \mathrm{H}_{2} \mathrm{O}+\mathrm{KCl}$

oxide. Figure 5c shows a scanning transmission electron microscope (STEM) high angle annular dark field (HAADF) image of the microstructure at higher magnification. The image shows a reaction zone, consisting of a mixture of oxide and remaining metal, including a darker fully oxidized region with voids (top right). The oxide inclusions in the reaction zone had an average size of the about $100 \mathrm{~nm}$. From the TEM/EDX analysis it was concluded that the particles consisted of $\mathrm{Fe}-\mathrm{Cr}$ oxide with about $45 \% \mathrm{Cr}$ and $55 \% \mathrm{Fe}$ (cationic). The remaining metal contained $\mathrm{Fe}$ and $\mathrm{Ni}$. The composition varied, the $\mathrm{Ni}$ content reaching up to $50 \%$. Small amounts of $\mathrm{Si}$ and $\mathrm{Mn}$ were detected in the oxide while small amounts of Mo were 


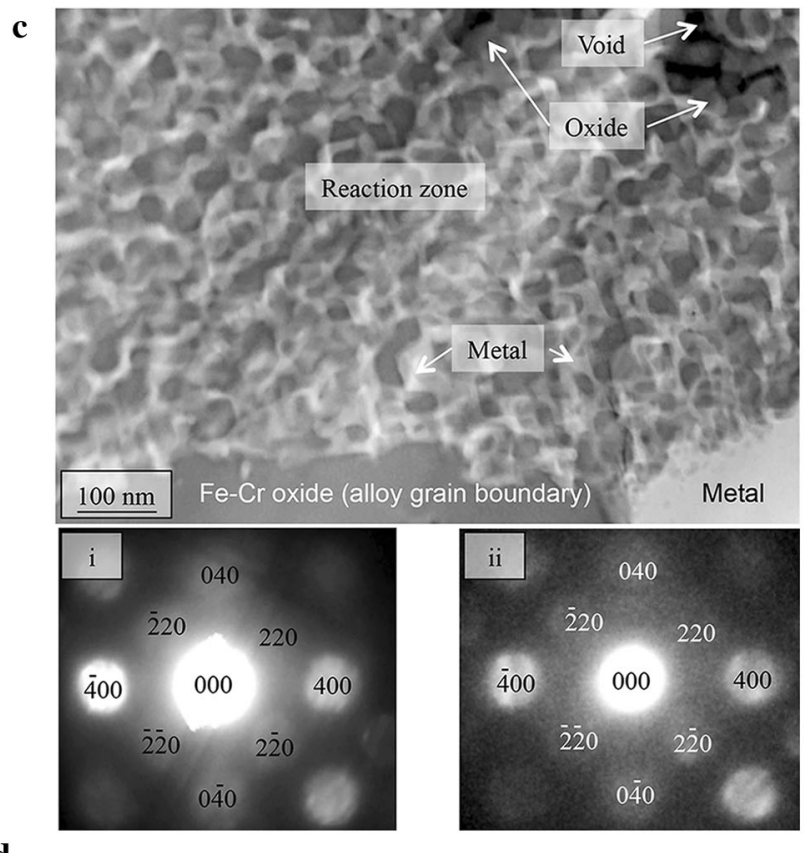

d
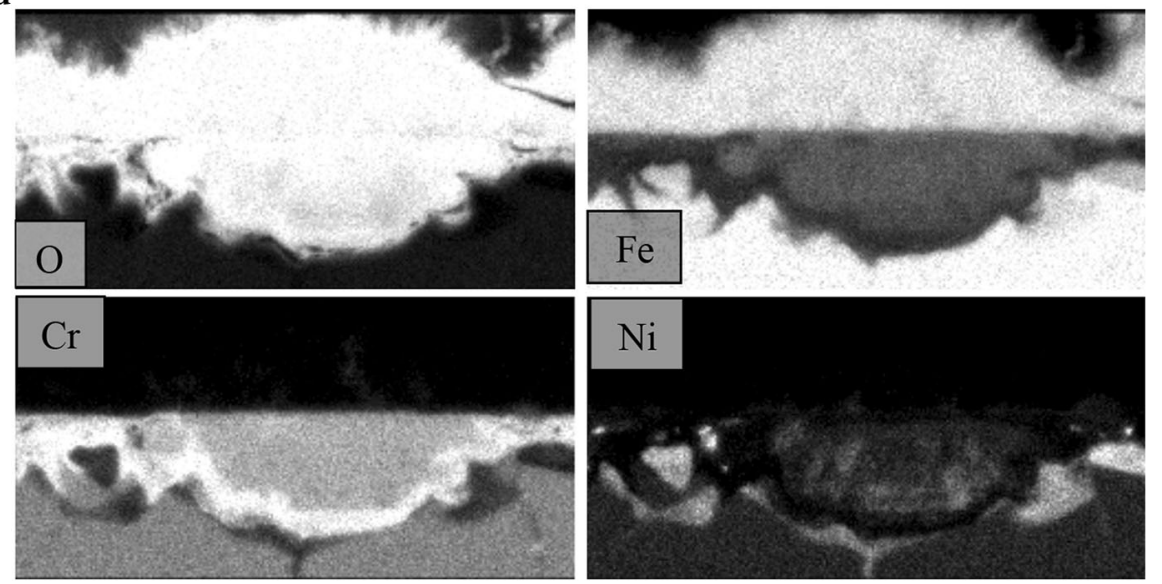

Fig. 5 continued

found in the remaining metal. The typical composition and size of the oxide particles in the reaction zone (=the internal oxide) is summarized in Table 3. It is challenging to measure the composition of particles having sizes similar to the thin foil thickness and the data in Table 3 are therefore based on interpreting the EDX analysis of a large number of particles ( $>100$ particles). In the lower left of the image in Fig. 5c there is a compact, fully oxidized region, which was connected to an alloy grain boundary. It contained about $60 \% \mathrm{Cr}$ and $40 \% \mathrm{Fe}$ (cationic) together with 1-2 at.\% $\mathrm{Mn}$ and $\mathrm{Si}$. Both the oxide precipitates in the reaction zone and the 
Table 3 Summary of the microstructure found in the reaction zones in this work and from literature (at.\% of the main elements, only cations and the average size of the internal oxides)

\begin{tabular}{llll}
\hline Alloy/environment & $\begin{array}{l}\text { Composition } \\
\text { reaction zone } \\
\text { (internal oxide) }\end{array}$ & $\begin{array}{l}\text { Composition } \\
\text { reaction zone } \\
\text { (metal) }\end{array}$ & $\begin{array}{l}\text { Size of internal } \\
\text { oxide precipitates } \\
(\mathrm{nm})\end{array}$ \\
\hline $\mathrm{FeCr}$ alloy/O $\mathrm{O}_{2}+\mathrm{H}_{2} \mathrm{O}[5] *$ & $45 \mathrm{Cr} 55 \mathrm{Fe}$ & $\mathrm{Fe}$ & $\approx 40-100$ \\
$304 \mathrm{~L} / \mathrm{O}_{2}+\mathrm{H}_{2} \mathrm{O}[9] *$ & $50 \mathrm{Cr} 50 \mathrm{Fe}$ & $50 \mathrm{Fe} 50 \mathrm{Ni}$ & $\approx 100$ \\
$304 \mathrm{~L} / \mathrm{O}_{2}+\mathrm{H}_{2} \mathrm{O}+\mathrm{KCl}$ & $45 \mathrm{Cr} 55 \mathrm{Fe}$ & $50 \mathrm{Fe} \mathrm{50Ni}$ & $\approx 100$ \\
$304 \mathrm{~L} / \mathrm{O}_{2}+\mathrm{H}_{2} \mathrm{O}+\mathrm{KCl}+\mathrm{SO}_{2}$ & $45 \mathrm{Cr} 55 \mathrm{Fe}$ & $50 \mathrm{Fe} 50 \mathrm{Ni}$ & $\approx 100$ \\
$304 \mathrm{~L} / \mathrm{H}_{2}+\mathrm{H}_{2} \mathrm{O}+\mathrm{Ar}$ & $45 \mathrm{Cr} 55 \mathrm{Fe}$ & $50 \mathrm{Fe} \mathrm{50Ni}$ & $\approx 30-100$ \\
$\mathrm{TP} 347 \mathrm{H} \mathrm{FG} / \mathrm{H}_{2}+\mathrm{H} 2 \mathrm{O}+\mathrm{O}_{2}[10] *$ & $50 \mathrm{Cr} 50 \mathrm{Fe}$ & $60 \mathrm{Fe} 30 \mathrm{Ni}$ & $\approx 100$ \\
\hline
\end{tabular}

* Data from literature

oxide in the fully oxidized grain boundary region were identified as spinel structure $\left(\mathrm{M}_{3} \mathrm{O}_{4}\right)$ by indexing convergent beam electron diffraction (CBED) patterns, see Fig. 5c (i, ii). The metal just below the reaction zone (lower right corner in Fig. 5c) was investigated by STEM/EELS and no oxygen signal was detected.

Figure 5d shows SEM/EDX elemental maps of the area labeled "5d" in Fig. 5a. The morphology of the crater region in $5 \mathrm{~d}$ was typical of about $90 \%$ of the inwardgrowing scale after $168 \mathrm{~h}$. At the scale/alloy interface there is a Cr-rich oxide similar to the grain boundary oxide in Fig. 5c. Above it there is a region with variable Ni concentration. This type of region was analyzed by SEM/EDX and was found to have an oxygen content of 55-60 at.\%. The SEM/EDX has insufficient resolution to identify the complex microstructure seen with TEM. However, the difference in contrast and the SEM/EDX data indicate that the area corresponds to a fully oxidized reaction zone, i.e., it consists of a mixture of internal oxide $(=\mathrm{FeCr}$ spinel oxide) precipitates and fully oxidized remaining FeNi metal (compare Fig. 5c). There were no indications of chlorine in the scale after breakaway [8].

$\mathrm{O}_{2}+\mathrm{H}_{2} \mathrm{O}+\mathrm{KCl}+\mathrm{SO}_{2}$

Both plan view imaging and mass gain kinetics (see above) indicate that the oxide scale was still thin and protective after $1 \mathrm{~h}$ exposure. While this scale was not investigated in detail, ion milled BIB cross-sections were prepared from samples exposed for 24 and $168 \mathrm{~h}$. After $24 \mathrm{~h}$ the scale in the ion-milled cross-section was in the range $0.1-2 \mu \mathrm{m}$ (not shown), representing both the remaining thin scale and the thicker scale shown in Fig. 3. The thick scale was duplex with an iron-rich outer part (about $75 \%$ of the scale thickness) and a FeCrNi-rich inner part. At the alloy grain boundaries the inward- and outward-growing parts of the scale had about the same thickness. Furthermore, about 5 at.\% $\mathrm{S}$ were detected beneath the inward growing oxide, at the metal/oxide interface. At this stage $(24 \mathrm{~h})$ there were no signs of formation of a reaction zone/internal oxidation in the millimetre wide crosssection. Figure 6a shows a BSE image of an ion-milled cross-section from a sample exposed for $168 \mathrm{~h}$. The scale was typically $2-4 \mu \mathrm{m}$ thick and the microstructure and composition of the scale were similar to the thick scale observed after $24 \mathrm{~h}$. 

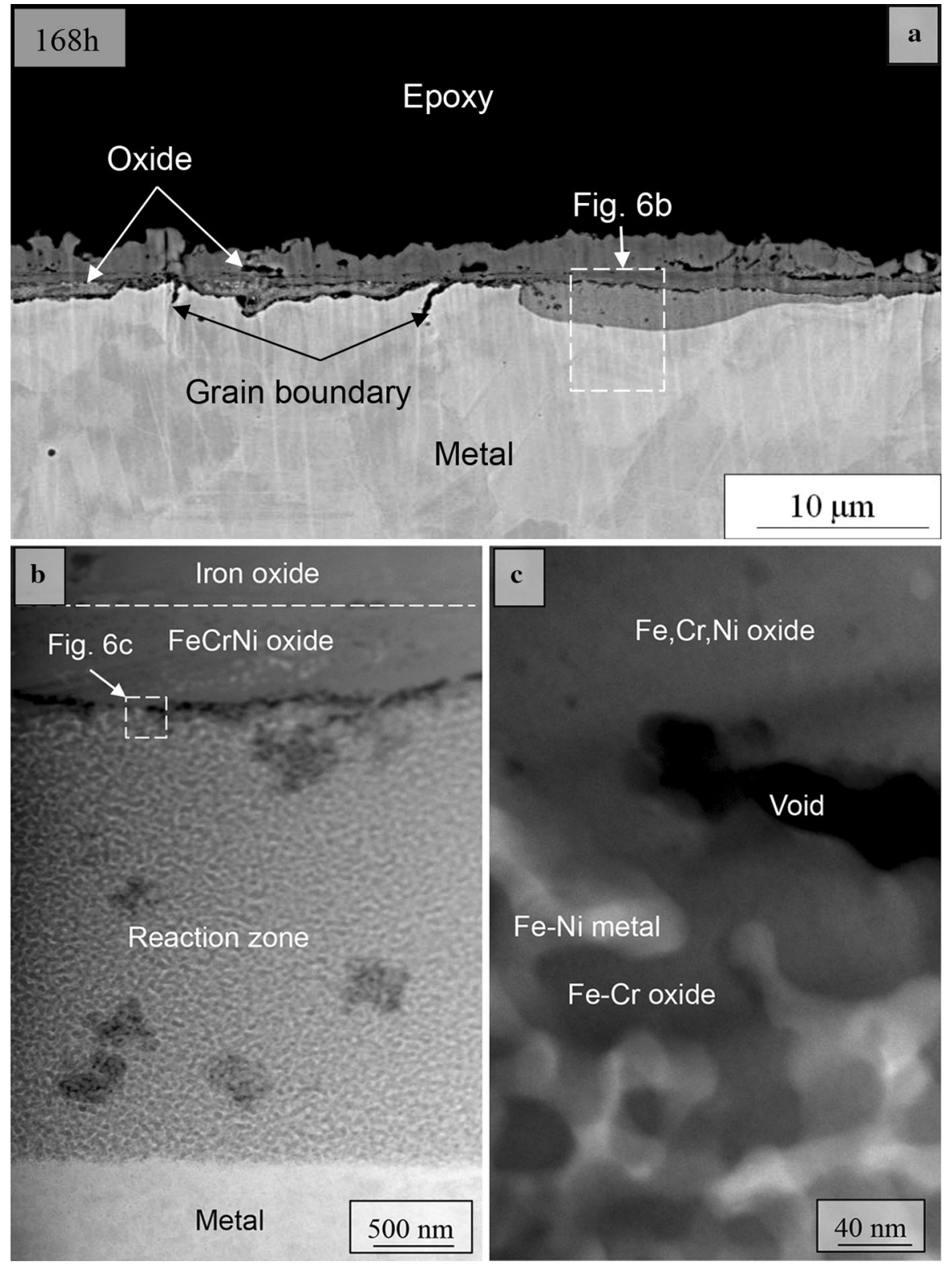

Fig. 6 a BSE image of a BIB cross-section of the 304L (18Cr-10Ni) sample exposed for $168 \mathrm{~h}$ in presence of $\mathrm{SO}_{2}$ at $600{ }^{\circ} \mathrm{C}$ in $5 \% \mathrm{O}_{2}+40 \% \mathrm{H}_{2} \mathrm{O}+\mathrm{KCl}$. The marked area is shown in higher magnification in $(\mathbf{b}, \mathbf{c})$. b, $\mathbf{c}$ HAADF image of a region similar to the marked region in (a). The inward growing oxide scale can be divided into a region of mixed oxide and metal, i.e. a reaction zone, and darker fully oxidized regions. $\mathbf{c}$ The marked region in (b) shown with higher magnification

However, in the alloy grain boundary regions the oxide penetrated deeper into the alloy (reaching 4-5 $\mu \mathrm{m}$ ) and some regions could be observed that were interpreted as reaction zones (internal oxidation). Figure $6 \mathrm{~b}$, c shows such a region at higher 
magnification. The upper section of the inward growing scale is fully oxidized and very similar to the scale found after $24 \mathrm{~h}$. It has a typical composition with about $60 \% \mathrm{Fe}, 30-35 \% \mathrm{Cr}$, up to $5 \% \mathrm{Ni}$ and small amounts of $\mathrm{Si}, \mathrm{Mn}$ and $\mathrm{Mo}$. The HAADF image indicates small variations in composition and/or void formation in parts of this layer and void formation at the oxide/reaction zone interface. Similar to Fig. $5 \mathrm{c}\left(\mathrm{KCl}\right.$ in the absence of $\left.\mathrm{SO}_{2}\right)$, the reaction zone consists of a mixture of internal oxide particles and remaining metal. Also, the size and composition of the remaining metal and the oxide are very similar to that observed in the corresponding exposure in the absence of $\mathrm{SO}_{2}$. Thus, the internal oxide consisted of $\mathrm{Fe}-\mathrm{Cr}$ oxide with about $45 \% \mathrm{Cr}$ and $55 \% \mathrm{Fe}$ (cationic) and the remaining $\mathrm{Fe}-\mathrm{Ni}$ metal inbetween the oxide particles contained up to $50 \% \mathrm{Ni}$. The composition of the reaction zone is summarized in Table 3. In addition, sulphur enrichments were observed at the alloy grain boundaries.

$\mathrm{H}_{2} \mathrm{O}+\mathrm{H}_{2}+\mathrm{Ar}$

The plan view images and mass gain kinetics indicate that the oxide scale has lost much of its protective properties already after $1 \mathrm{~h}$ in this environment. The initial stages of breakaway and first steps of propagation have been investigated in detail elsewhere [30, 31], showing an outward growing magnetite layer above a $\mathrm{Cr}$ rich remnant of the initially formed scale after $1 \mathrm{~h}$. Further down into the scale an inward growing reaction zone was observed [30]. After $24 \mathrm{~h}$ the scale had grown to about 8 $\mu \mathrm{m}$ and was made up of an outward growing magnetite layer (about $50 \%$ of the scale thickness) and an inward growing part consisting of both spinel oxide and reaction zone regions (internal oxidation) [30]. The spinel oxide regions were found both immediately below the original steel surface and at alloy grain boundaries [23]. The present investigation after $72 \mathrm{~h}$ exposure shows all the features previously reported after $24 \mathrm{~h}$ exposure, see BSE image of a mechanically polished crosssection in Fig. 7a. At this stage the scale has grown to about $12 \mu \mathrm{m}$ and exhibits an outward growing magnetite layer. The inward-growing part of the scale is dominated by regions that are not fully oxidized according to SEM/EDX (30-40 at.\% O), being interpreted as reaction zones (=internal oxidation). The microstructure of the inward growing scale was investigated with the TEM both in the middle of an alloy grain and at an alloy grain boundary (marked regions in Fig. 7a). Figure $7 \mathrm{~b}$ shows a HAADF image of a reaction zone located in the middle of an alloy grain at higher magnification. The top part of the inward growing scale is fully oxidized but it is very thin. The fully oxidized part consisted of iron chromium oxide (about $70 \% \mathrm{Fe}$ and $30 \% \mathrm{Cr}$ ). However, the composition varies and in some positions the initial $\mathrm{Cr}$ rich oxide could be observed above a region consisting of $\mathrm{Ni}$ rich metal (up to $70 \% \mathrm{Ni}$ and $30 \% \mathrm{Fe}$ ) at the former metal/oxide interface. The reaction zone consisted of a mixture of internal oxide particles and remaining metal. While the internal oxide precipitates were smaller (about 30-100 nm) than in the high $\mathrm{PO}_{2}$ environments (compare Fig. 5c), the composition of both the remaining metal and the oxide precipitate was similar to that observed in the other environments. The smaller size made the analysis even more difficult but the analysis showed that the oxide precipitates consisted of $\mathrm{Fe}-\mathrm{Cr}$ oxide with about 


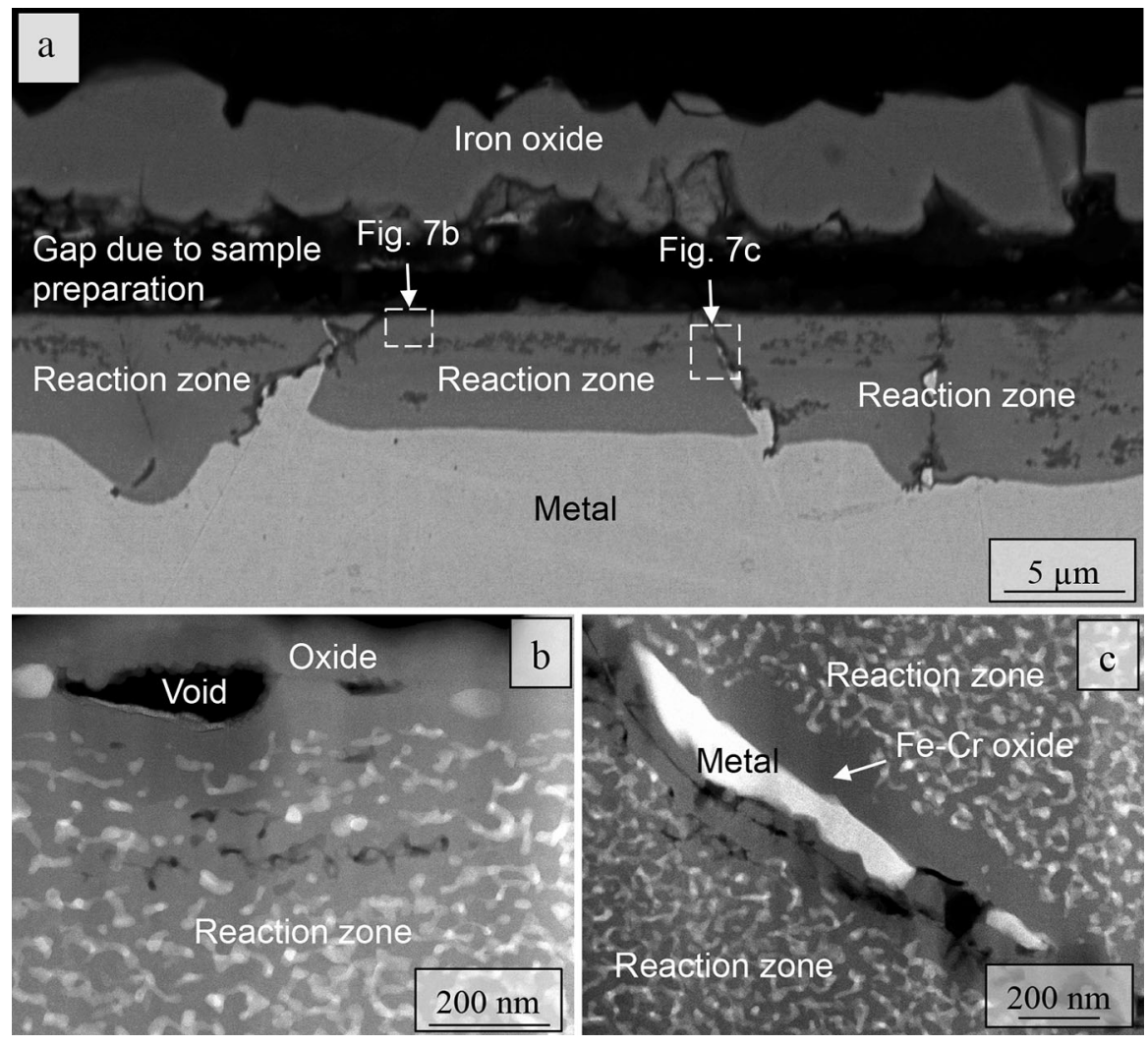

Fig. 7 a BSE image of a polished cross-section of the $304 \mathrm{~L}(18 \mathrm{Cr}-8 \mathrm{Ni})$ sample exposed for $72 \mathrm{~h}$ in $10 \% \mathrm{H}_{2}-20 \% \mathrm{H}_{2} \mathrm{O}-\mathrm{Ar}$. The marked areas are shown in higher magnification in b, $\mathbf{c}$. b HAADF image of a region similar to the marked area in (a). The inward growing oxide scale can be divided into a region of mixed oxide and metal, i.e. a reaction zone, and darker fully oxidized regions. $\mathbf{c}$ The marked region in (a) covering an alloy grain boundary region shown with higher magnification

45-50\% $\mathrm{Cr}$ and 50-55 \% Fe (cationic). The composition of the remaining $\mathrm{Fe}-\mathrm{Ni}$ rich metal varied, the $\mathrm{Ni}$ content being somewhat lower than observed on the $18 \mathrm{Cr}-$ $10 \mathrm{Ni}$ alloy. Close to the alloy grain boundary, a fully oxidized region could be observed, see HAADF image in Fig. 7c. It contained approximately $35 \% \mathrm{Fe}$ and $65 \% \mathrm{Cr}$ and was surrounded by $\mathrm{Ni}$ rich metal with up to $70 \% \mathrm{Ni}$ and $30 \% \mathrm{Fe}$.

$\mathrm{K}_{2} \mathrm{CO}_{3}+\mathrm{O}_{2}$

Samples coated with small amounts of $\mathrm{K}_{2} \mathrm{CO}_{3}$ were exposed for 24 and $168 \mathrm{~h}$ in dry oxygen. The analysis was performed on the $168 \mathrm{~h}$ exposure in order to be able to study the microstructure formed without water vapor/chlorine and no plan view or detailed investigations were performed after shorter times. Figure 8 shows a BSE image of a BIB cross-section ion milled through the oxide scale and into the alloy. The BSE image shows that the scale microstructure is very similar to that observed 


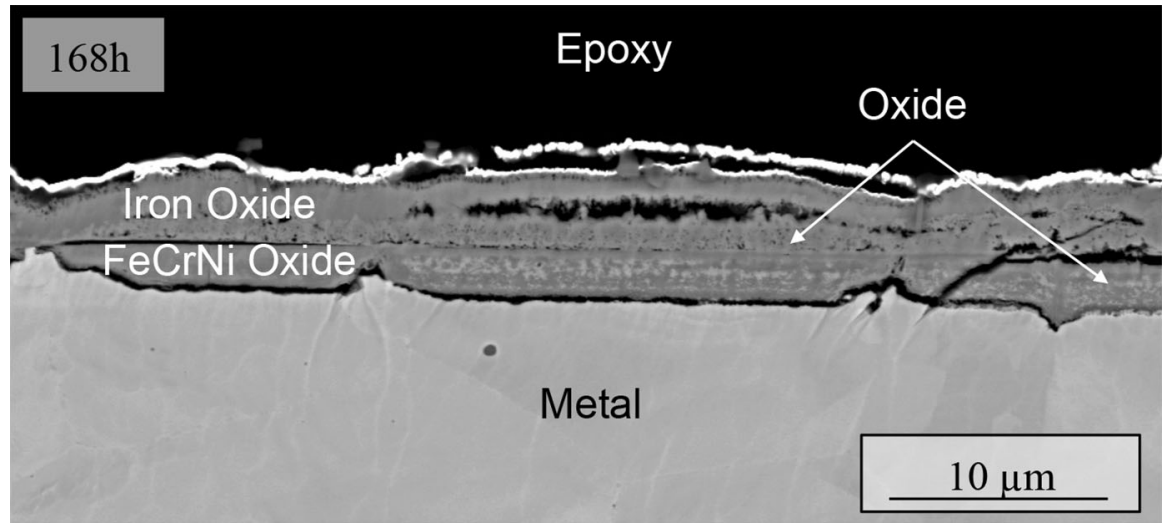

Fig. 8 BSE image of an ion milled cross-section of the 304L (18Cr-10Ni) sample exposed for $168 \mathrm{~h}$ at $600{ }^{\circ} \mathrm{C}$ in $\mathrm{O}_{2}+\mathrm{K}_{2} \mathrm{CO}_{3}$. The scale can be divided into an outward growing part consisting of iron oxide and an inward growing more complex oxide (FeCrNi oxide)

in the other environments after breakaway (compare Figs. 5, 6). Thus, the scale consists of an outward growing layer consisting of iron oxide and an inward growing more complex oxide (FeCrNi oxide). In the top part of the outward growing iron oxide layer small amounts of potassium were observed (SEM/EDX). The outward- growing and inward-growing scale layers had similar thickness, the total scale thickness ranging from about 3 to $6 \mu \mathrm{m}$. The BSE image indicates that the inward growing scale has a complicated microstructure with alternating bright and dark areas, being very similar to samples exposed in the other environments, indicating the formation of reaction zones. The complicated microstructure was verified by SEM/EDX, which showed that the bright parts in the inward growing $\mathrm{FeCrNi}$ oxide were high in $\mathrm{Ni}$ even though the limited resolution made it impossible to measure the composition accurately.

\section{Discussion}

\section{General Observations}

It is well known that stainless steels, e.g. alloy $304 \mathrm{~L}$, form a thin protective oxide scale in dry oxygen at $600{ }^{\circ} \mathrm{C}$. The scale is well-characterized, consisting of a $\left(\left(\mathrm{Cr}_{\mathrm{x}} \mathrm{Fe}_{1-\mathrm{x}}\right)_{2} \mathrm{O}_{3}\right)$ inner layer with about $70 \% \mathrm{Cr}$ (cation \%) and an iron-rich outer part [17, 32-34]. In more corrosive environments containing, e.g. water vapor, alkali and/or chlorine the $\left(\left(\mathrm{Cr}_{\mathrm{x}} \mathrm{Fe}_{1-\mathrm{x}}\right)_{2} \mathrm{O}_{3}\right)$ scale may lose its protective properties resulting in breakaway oxidation, see e.g., [8, 9, 35]. Breakaway tends to be triggered by $\mathrm{Cr}$ depletion of the scale and of the substrate. Hence, due to faster diffusion of $\mathrm{Cr}$ at alloy grain boundaries, breakaway in austenitic steels usually starts at the center of alloy grains while the oxide on alloy grain boundary regions is more resistant, see e.g. [8,9]. This general trend is in accordance with the oxidation 
kinetics and surface morphologies observed at high oxygen activity in this study, see e.g. Figs. 2 and 5a, while no clear difference between the alloy grains and grain boundaries was observed in $\mathrm{H}_{2} \mathrm{O}+\mathrm{H}_{2}$ environment see Fig. 4. The thin protective scale broke down in all environments investigated but the incubation time differed, see Fig. 1 and Table 2. The results show that the breakdown is initially localized in all cases, see Figs. 2, 3 and 4. However, with longer exposure time the entire surface becomes covered with a thick, fast growing scale. The incubation time (an interpretation of the plan view images since the localized behavior makes it impossible to use the mass gain data) and the growth rate subsequent to breakaway are summarized in Table 2.

\section{Mechanisms of Breakdown of the Thin Protective Scale}

Adding water vapour or alkali to an $\mathrm{O}_{2}$ containing environment is known to accelerate the corrosion of chromia-forming steels. Previously, the vaporization of chromium(VI) oxide hydroxide was shown to cause breakaway oxidation of $\mathrm{Fe}-\mathrm{Cr}$ model alloys and commercial stainless steels in environments containing $\mathrm{O}_{2}+\mathrm{H}_{2} \mathrm{O}$ at high temperatures [4, 18, 19]. In an analogous manner, the breakdown of the initial protective oxide in the presence of alkali [8] was explained by the formation of alkali chromate in a reaction with the protective scale. Addition of small amounts of sulfur dioxide has been shown to prolong the incubation time for breakaway oxidation in the presence of $\mathrm{KCl}$ and to slow down scale growth after breakaway [20]. Both chromium (VI) oxide hydroxide volatilization and alkali chromate formation cause breakaway oxidation by depleting the oxide scale and the substrate in chromium. In this study, the breakdown of the protective scale in $\mathrm{O}_{2}+\mathrm{H}_{2} \mathrm{O}$ environment can be explained by chromium (VI) oxide hydroxide volatilization, see Figs. 1, 2 and 3. At low oxygen activities, evaporation of chromium (VI) oxide hydroxide is negligible and the accelerated oxidation of stainless steels in $\mathrm{H}_{2}+\mathrm{H}_{2} \mathrm{O}$ environment must have other causes. Various explanations have been suggested for the effect of water vapor at low oxygen activity [16, 21-23]. Tveten et al. [22] suggested that exposure to water vapor results in uptake of protons which influence the transport properties of the oxide. Essuman et al. [16] argued that hydrogen dissolution into the alloy enhances the inward diffusion of oxygen in the alloy, promoting internal oxidation and hindering the formation of an external chromia scale. Recently, a new mechanism was proposed explaining the corrosiveness of $\mathrm{H}_{2}+\mathrm{H}_{2} \mathrm{O}$ environments towards chromia-forming alloys. It was argued that the low oxygen activity causes the $\mathrm{Cr}$-rich $(\mathrm{Fe}, \mathrm{Cr})_{2} \mathrm{O}_{3}$ scale to transform into faster growing $\mathrm{Cr}_{2} \mathrm{O}_{3}$. This causes a deeper $\mathrm{Cr}$ depletion of the substrate that allows $\mathrm{Fe}$ at the alloy/scale interface to oxidize [31]. A study of $\mathrm{K}_{2} \mathrm{CO}_{3}$-coated steels in oxidizing environments without water vapor or chlorine also shows breakaway oxidation. This was explained by the formation of alkali chromate in a reaction with the protective scale [36]. The different observations concerning mechanisms, incubation times and growth rate after breakaway oxidation in this work are summarized in Table 2. 


\section{Propagation After Breakaway Oxidation}

The oxide scale formed directly after breakdown of the slow-growing $\left(\mathrm{Cr}_{\mathrm{x}} \mathrm{Fe}_{1-\mathrm{x}}\right)_{2-}$ $\mathrm{O}_{3}$ scale has been characterized in a number of papers $[5,7-9,15,35]$ in the temperature range 500-900 ${ }^{\circ} \mathrm{C}$ and involving several different environments and alloys. The oxide scale typically consists of an inward-growing layer consisting of spinel oxide + reaction zones and an outward-growing iron-rich layer, the two layers being separated by the original metal/oxide interface. This is in good agreement with the present observations after long exposure times, see Figs. 5a, 6a, $7 \mathrm{a}$ and 8 . The characteristic morphology may be explained by the different diffusivities of $\mathrm{Cr}^{3+}$ and $\mathrm{Fe}^{2+}$ in the spinel phase [37, 38]. Thus, $\mathrm{Cr}^{3+}$ ions diffuse several orders of magnitude slower than $\mathrm{Fe}^{2+}$ and $\mathrm{O}^{2-}$ in the spinel, resulting in an outward growing hematite/magnetite layer and an inward growing spinel.

\section{The Outward Growing Iron Oxide}

The outer layer consisted of almost pure hematite in the high oxygen activity environments and magnetite in $\mathrm{H}_{2}+\mathrm{H}_{2} \mathrm{O}$, see Figs. 5a, 6a, 7a, and 8. The prevalence of magnetite in contact with $\mathrm{H}_{2}+\mathrm{H}_{2} \mathrm{O}$ (oxygen activity about $10^{-24}$ [1]) is expected. The hematite layer morphology was similar in all the high oxygen environments, the grain size being much smaller than for magnetite, see Figs. 2, 3, 4 and [8]. This is in agreement with earlier studies on oxidation of iron at $500{ }^{\circ} \mathrm{C}$ in $\mathrm{H}_{2} \mathrm{O}(\mathrm{g})$ and in dry air [39]. It has been reported that the growth rate of the iron oxide layer in high oxygen activity at $500-600{ }^{\circ} \mathrm{C}$ is accelerated by water vapor because of changes in the transport properties of the hematite layer [40-42]. This may explain why the scale formed after breakaway oxidation grew slower in $\mathrm{O}_{2}+\mathrm{K}_{2} \mathrm{CO}_{3}$ environment than in the $\mathrm{O}_{2}+\mathrm{H}_{2} \mathrm{O}+\mathrm{KCl}$ exposure (Figs. 1, 5a, 8). In contrast, addition of small amounts of $\mathrm{SO}_{2}$ has been reported to decrease the growth rate of iron oxide scales due to formation of sulphate on top of the hematite layer, blocking the surface sites necessary for $\mathrm{O}_{2}$ reduction [40]. Accordingly, the growth rate after breakaway oxidation in the $\mathrm{O}_{2}+\mathrm{H}_{2} \mathrm{O}+\mathrm{KCl}+\mathrm{SO}_{2}$ exposure was slower than in the $\mathrm{O}_{2}+\mathrm{H}_{2} \mathrm{O}+\mathrm{KCl}$ exposure (compare Figs. 5a, 6a; Table 2). This implies that $\mathrm{SO}_{2}$ not only delays the breakdown of the protective scale by converting the corrosive $\mathrm{KCl}$ to non-reactive $\mathrm{K}_{2} \mathrm{SO}_{4}$, it also slows down the growth of the iron-rich scale after breakaway [20].

\section{The Inward Growing Spinel Oxide}

While the outward growing scale consisted of nearly pure iron oxide in all cases, the inward growing scale had a much more complex microstructure/composition, see Figs. 5, 6, and 7. Also, the detailed investigation showed that the main microstructural features were similar, irrespective of environment/alloy grade. Thus, in all cases the inward growing scale formed after breakaway consisted of fully oxidized regions on one hand, and "reaction zones" consisting of mixtures of nanosize oxide particles and remaining metal, on the other (Figs. 5, 6, 7, and [4]). 
This similarity suggests that the mechanisms of formation and growth of the inwardgrowing scale are also similar.

An examination of the inward-growing scale formed in the three high $\mathrm{PO}_{2}$ environments that caused breakaway oxidation $\left(\mathrm{O}_{2}+\mathrm{H}_{2} \mathrm{O}, \mathrm{O}_{2}+\mathrm{KCl}+\mathrm{H}_{2} \mathrm{O}\right.$ and $\mathrm{O}_{2}+\mathrm{KCl}+\mathrm{H}_{2} \mathrm{O}+\mathrm{SO}_{2}$ ) shows that the new scale formed immediately below the original metal/oxide interface is always fully oxidized, consisting of FeCrNi spinel (see e.g., Figure 6a). The cationic composition of this oxide layer corresponds to the alloy composition, taking into account the removal of iron by outward diffusion to form the iron oxide at the top of the scale. These observations are in good agreement with earlier studies on $\mathrm{FeCr}$ alloys and stainless steels exposed in $\mathrm{O}_{2}+\mathrm{H}_{2} \mathrm{O}$ [4-9] and it may be concluded that the formation of a fully oxidized inward growing layer is the first stage in the process of breakaway oxidation in these cases.

The observation that this oxide layer forms before the onset of internal oxidation and that it is in contact with the alloy where internal oxidation occurs, implies that it plays a seminal role for internal oxidation. Thus, it is suggested to be involved in the process of oxygen dissolution into the alloy, which is considered to be the first step in internal oxidation [2]. A comparison of this "first inward oxide layer" formed in the three high $\mathrm{PO}_{2}$ environments shows that it is considerably thicker in $\mathrm{O}_{2}+\mathrm{H}_{2} \mathrm{O}$ [9] and $\mathrm{O}_{2}+\mathrm{KCl}+\mathrm{H}_{2} \mathrm{O}$ exposures than in $\mathrm{O}_{2}+\mathrm{H}_{2} \mathrm{O}+\mathrm{KCl}+\mathrm{SO}_{2}$ environment (compare Figs. 5a, 6; Table 2). The observation that the presence of $\mathrm{SO}_{2}$ resulted in a thinner inward growing oxide is in accordance with the behavior of iron at $500{ }^{\circ} \mathrm{C}$ where traces of $\mathrm{SO}_{2}$ in $\mathrm{O}_{2}$ reportedly resulted in a reduced inward flux of oxygen through the scale [39].

As noted above, internal oxidation appears to be the second step in the breakaway process in the high $\mathrm{PO}_{2}$ environments. Table 3 shows that the composition of the internal oxide is similar in all environments studied and on both $304 \mathrm{~L}$ grades. Also, the phase and chemical composition of the internal oxide is consistent with earlier observations on internal oxidation of $\mathrm{Fe}-\mathrm{Cr}$ model alloys [5] and commercial alloys $[9,10]$ (Table 3). According to the $\mathrm{Fe}-\mathrm{Cr}-\mathrm{O}$ phase diagram at $600{ }^{\circ} \mathrm{C}$, reported in [4], the $\mathrm{FeCr}$ spinel oxide exhibits partial solid solubility, a miscibility gap appearing between 9 and 43 at.\% $\mathrm{Cr}$ (cationic). The high $\mathrm{Cr}$ boundary of the miscibility gap thus more or less coincides with the composition of the internal oxide precipitates in $304 \mathrm{~L}$, see Table 3. The situation for $\mathrm{FeCrNi}$ alloys is analogous, a miscibility gap appearing in the FeCrNi spinel oxide (see below, i.e., Figure 9).

In comparison to the high $\mathrm{PO}_{2}$ environments, the $\mathrm{H}_{2}+\mathrm{H}_{2} \mathrm{O}$ environment is more effective in promoting the formation of a reaction zone (internal oxidation). Also, the reaction zone either appears immediately below the old metal/oxide interface or is separated from it by only a very thin $(50-100 \mathrm{~nm})$ oxide layer, see Fig. 7a, b. It may be noted that in $\mathrm{H}_{2}+\mathrm{H}_{2} \mathrm{O}$ environment, this oxide layer consisted of $\mathrm{Fe}-\mathrm{Cr}$ oxide and not FeCrNi spinel as in the high $\mathrm{PO}_{2}$ environments. Figure 9 shows the calculated equilibrium composition of the spinel oxide formed by an alloy with the 304 $\mathrm{L}$ composition at $600{ }^{\circ} \mathrm{C}$, as a function of $\mathrm{O}_{2}$ activity (note that only spinel oxide is shown). It shows that an oxygen activity $>10^{-24}$ is necessary for the Nicontaining spinel to be thermodynamically favored. In contrast, the equilibrium oxygen activity at the scale/alloy interface is certainly far below that value (e.g., the 


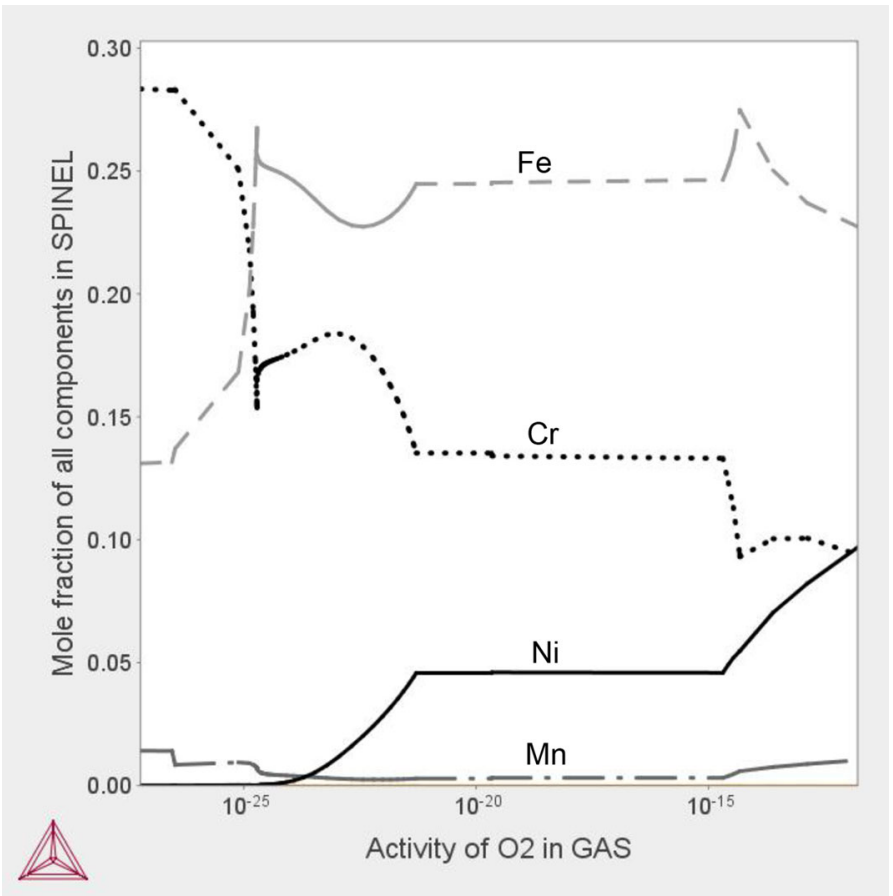

Fig. 9 Oxygen activity versus mole fraction of all components of 304L alloy (18-10) in the spinel type structure $\left(\mathrm{M}_{3} \mathrm{O}_{4}\right)$ at $600{ }^{\circ} \mathrm{C}$ calculated using the THERMO-CALC program with the database TCFE7

$\mathrm{Cr}_{2} \mathrm{O}_{3} / \mathrm{Cr}$ equilibrium oxygen activity is about $10^{-35}$ ). This implies that, at the start of the breakaway event in the high $\mathrm{PO}_{2}$ environments, the oxygen activity at the interface between the thin protective oxide and the alloy is much higher than the oxide/stainless steel equilibrium. Conversely, the observation that $\mathrm{Ni}^{2+}$ did not enter the corresponding "first inward oxide layer" in $\mathrm{H}_{2}+\mathrm{H}_{2} \mathrm{O}$ environment implies that the oxygen activity at the interface in question is closer to the equilibrium value in that case. It may be noted that in a corroding system, the oxygen activities must deviate from the equilibrium values. Thus, the scale/alloy interface must have higher oxygen potential than the metal/oxide equilibrium while the oxygen activity at the oxide/gas interface has to be lower than that of the gas. The observations on the composition of the "first inward oxide layer" imply that the oxygen activity at the interface between the thin protective oxide and the alloy is higher (and hence farther from equilibrium) in the $\mathrm{O}_{2}$-containing experiments than in $\mathrm{H}_{2}+\mathrm{H}_{2} \mathrm{O}$. Indeed, this is expected because the oxygen activity in the $\mathrm{H}_{2}+\mathrm{H}_{2} \mathrm{O}$ gas is rather low at about $10^{-24}$ compared to about 1 in the high $\mathrm{O}_{2}$ activity experiments. The observation that the spinel oxide precipitated in the reaction zone did not contain $\mathrm{Ni}$ implies that the oxygen activity in that part of the alloy was $<10^{-24}$, regardless of the gas composition. The different stages of propagation following breakaway oxidation of Fe, Cr, (Ni) alloys in both high and low $\mathrm{PO}_{2}$ are summarized in Fig. 10. 


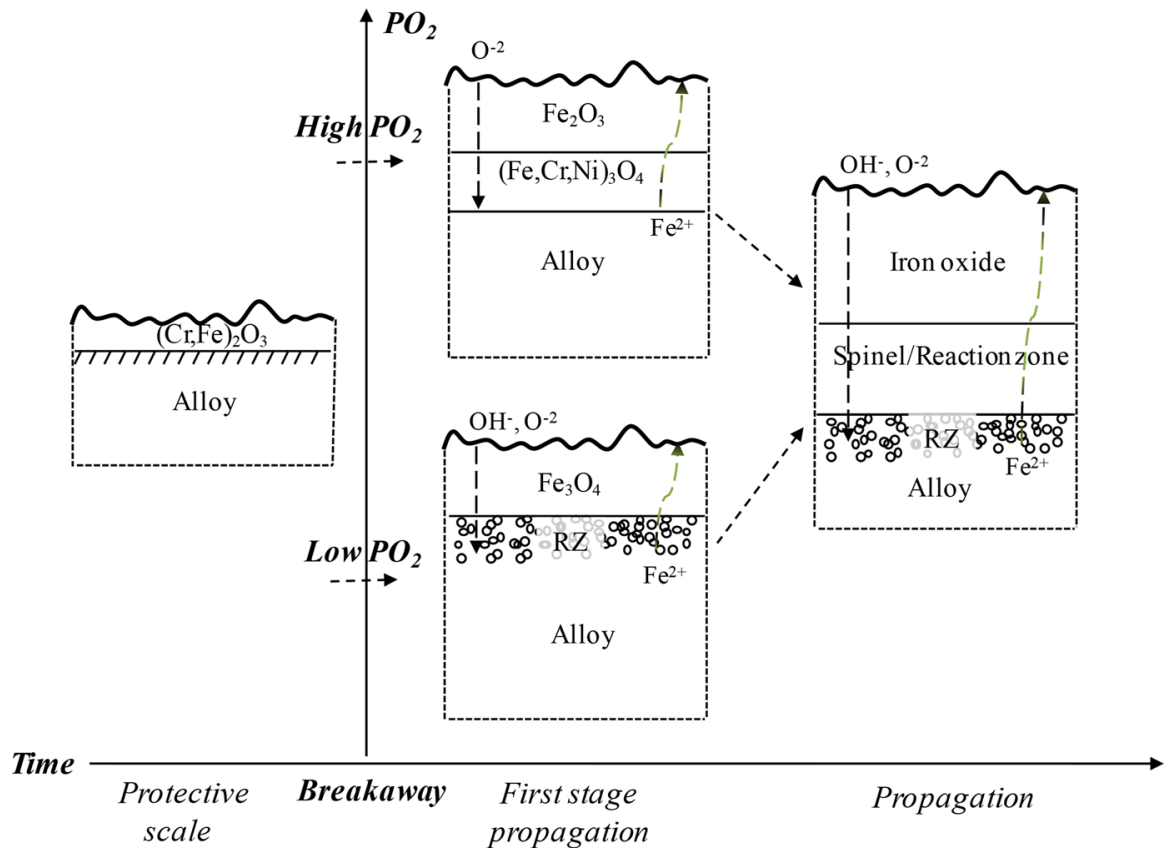

Fig. 10 A schematic drawing summarizing the different stages of propagation following breakaway oxidation of $\mathrm{Fe}, \mathrm{Cr},(\mathrm{Ni})$ alloys in both high and low $\mathrm{PO}_{2}$. First stage of propagation after breakaway: (high $\mathrm{PO}_{2}$ environments) the new scale formed immediately below the original metal/oxide interface is always fully oxidized, consisting of $\mathrm{FeCrNi}$ spinel. (low $\mathrm{PO}_{2}$ environments) $\mathrm{Ni}^{2+}$ did not enter the corresponding "first inward oxide layer" and internal oxidation is promoted. After longer exposure times the composition of the internal oxide (RZ) is similar in all environments studied and on both 304L grades

In the high $\mathrm{PO}_{2}$ exposures, the reaction zones tend to become fully oxidized with time $\left(\mathrm{O}_{2}+\mathrm{KCl}+\mathrm{H}_{2} \mathrm{O}\right.$, see Fig. 5d), implying that the oxygen activity has increased so as to enable the remaining FeNi metal to oxidize. As expected, this did not happen in the $\mathrm{H}_{2}+\mathrm{H}_{2} \mathrm{O}$ environment (see Fig. 7a-c) due to the low oxygen potential in the gas. It may be noted that the fully oxidized reaction zone in Fig. $5 \mathrm{~d}$ is separated from the alloy by a layer of Cr-rich oxide situated on top of a layer of $\mathrm{Ni}$ rich metal. This "new" external oxide beneath the fully oxidized reaction zone consists of $\mathrm{FeCr}$ spinel oxide.

The composition of the spinel oxide precipitate in the reaction zone is close to the high $\mathrm{Cr}$ boundary of the miscibility gap. As noted above, it is challenging to measure the composition of these oxide inclusions and the occurrence of precipitates with higher $\mathrm{Cr} / \mathrm{Fe}$ ratios cannot be ruled out. Also, the composition of the precipitates may differ from the equilibrium value because of e.g. the kinetics of nucleation and growth. Anyway, the composition measured (about $45 \% \mathrm{Cr}$ and $55 \% \mathrm{Fe}$ ) implies that the oxygen activity in the reaction zone is high in comparison to the metal/oxide equilibrium value (see Fig. 9), as expected for an alloy suffering internal oxidation. The alloy beneath the reaction zone was investigated by STEM/ EELS to search for traces of oxygen in the alloy, ahead of the reaction zone. 
However, despite a detection level of about $1 \mathrm{ppm}$ in STEM/EELS [43] no signal from oxygen was detected.

The internal oxide particles were somewhat smaller in the $\mathrm{H}_{2}+\mathrm{H}_{2} \mathrm{O}$ experiment than in the other environments/alloys, see Table 3. This may be related to the lower $\mathrm{Ni}$ content in the alloy or to the environment, see below. SEM/EDX analysis of the scale cross-sections showed that the inward growing scale, consisting of spinel oxide areas plus reaction zones, was iron-depleted compared to the alloy composition. This is because the inward-growing scale supplies iron to the outward growing iron oxide. (Note that fully oxidized areas and reaction zones cannot be resolved by SEM/EDX).

To summarize, the characteristic features in the complex microstructures observed on 304L type stainless steel after breakaway oxidation are governed by certain properties of the $\mathrm{FeCr}(\mathrm{Ni})-\mathrm{O}$ system and are more or less independent of the corrosive environment. Thus, the different diffusivities of $\mathrm{Cr}^{3+}$ and $\mathrm{Fe}^{2+}$ in the spinel phase result in a layered scale with outward growing iron oxide and inward growing spinel. Also, the thermodynamics of the $\mathrm{FeCr}$ spinel oxide system, including its miscibility gap; (a) explain the composition of the internal oxide particles; (b) explain why $\mathrm{Ni}$ enters the inward-growing spinel in $\mathrm{H}_{2}+\mathrm{H}_{2} \mathrm{O}$ environment but not in the high $\mathrm{PO}_{2}$ experiments.

\section{Influence of the Formation of Reactions Zones on Oxidation Properties/ Kinetics}

As described above, the microstructure of the inward growing scale formed after breakaway includes regions termed reaction zones having similar microstructure in all environments, see Figs. 5, 6, and 7. In $\mathrm{H}_{2}+\mathrm{H}_{2} \mathrm{O}$ environment these regions remain as mixed oxide/metal also after long exposure times while they tend to become fully oxidized in the high oxygen activity exposures, see Figs. $5 \mathrm{~d}, 7 \mathrm{a}-\mathrm{c}$ and [10]. The characteristic microstructure of the reaction zones may influence the properties/oxidation kinetics in the following ways:

- It creates a network of oxide/metal or oxide/oxide interfaces which can act as fast transport paths for ions, e.g., for $\mathrm{Fe}^{2+}$ ions moving towards the scale surface.

- The remaining Fe/Ni metal between the oxide precipitates may form voids when acting as a source of ions for the outward-growing scale. Indications of this have been observed on FeCr model alloys [5] and can be seen in Figs. 6b and 7b. Void formation may cause spallation.

The incubation time to breakaway and the growth rate after breakaway oxidation varies in the different environments, see Fig. 1a, b and Table 2. The fastest oxidation rate after breakaway was observed in the $\mathrm{H}_{2}+\mathrm{H}_{2} \mathrm{O}$ experiment, see Fig. 1b. The absence of hematite on the surface in combination with the microstructure of the inward growing scale may explain this. Diffusion through magnetite is known to be faster than through hematite [44, 45]. Also, the microstructural investigation showed that the ratio: reaction zone/fully oxidized 
spinel oxide, was higher in $\mathrm{H}_{2}+\mathrm{H}_{2} \mathrm{O}$ (compare Figs. 5a, 7c). The inward growing scale developed in $\mathrm{H}_{2}+\mathrm{H}_{2} \mathrm{O}$ therefore provides little protection.

\section{Influence of the Environment in the Propagation Stage (After Breakaway Oxidation)}

The results imply that the general features and microstructure of the scales formed after breakaway are not directly linked to the environment that causes breakaway. Instead they are governed by the general characteristics of $\mathrm{FeCr}(\mathrm{Ni})$ alloys and oxides, i.e. the thermodynamic properties of the $\mathrm{FeCrNi}-\mathrm{O}$ system (Fig. 9 and [4]) and the diffusivity of cations in the spinel [37,38]. However, the corrosive species that trigger breakaway oxidation of stainless steels may influence the rate of oxidation after breakaway. As noted above, depending on the gas environment, the outward growing iron oxide scale forms hematite or magnetite, influencing the transport properties. Also, the properties and growth of iron oxide can influence the microstructure of the inward growing scale, e.g. as in the case of $\mathrm{SO}_{2}$ which slows down the inward flux of oxide ions, causing the reaction zones to form closer to the original metal surface. The results indicate that the presence of $\mathrm{KCl}$ decreased the time to breakaway because of the reaction of potassium ions with chromia in the protective scale and that it did not strongly influence the propagation stage, see Fig. 1a. While it is well known that $\mathrm{Cl}$ is very corrosive in these environments and temperatures [1] significant levels of $\mathrm{Cl}$ were lacking in the scale after breakaway [8]. It has been suggested that the prolonged incubation time in the presence of $\mathrm{SO}_{2}$ is explained by the conversion of reactive $\mathrm{KCl}$ to non-reactive potassium sulfate, resulting in the formation of less potassium chromate [20].

Water vapor is present in three of the four environments and is known to influence the oxidation in several ways as mentioned in the introduction. Thus, the presence of $\mathrm{H}_{2} \mathrm{O}$ may increase the growth rate of the iron oxide formed after breakaway oxidation as described above. Also, $\mathrm{H}_{2} \mathrm{O}$ has been suggested to influence the solubility and/or diffusivity of oxygen in the alloy, causing increased internal oxidation $[11,13,17]$. This study shows that, at high oxygen activity, the formation of a reaction zone (internal oxidation) does not occur directly after breakaway but is preceded by the formation of an inward-growing $\mathrm{FeCrNi}$ spinel oxide see Figs. 5, 6, and 7. However, in $\mathrm{H}_{2}+\mathrm{H}_{2} \mathrm{O}$ environment it is difficult to interpret the sequence of events because internal oxidation occurred very close to the original interface, see Fig. $7 b$.

To elucidate the role of $\mathrm{H}_{2} \mathrm{O}$ on scale microstructure in the propagation step, breakaway was induced on samples by coating with $\mathrm{K}_{2} \mathrm{CO}_{3}$ and exposing in dry $\mathrm{O}_{2}$ at $600{ }^{\circ} \mathrm{C}$ for 24 and $168 \mathrm{~h}$. The microstructural investigation showed that, while the scale was relatively thin it exhibited all the characteristic features of the breakaway scale in high $\mathrm{PO}_{2}$ environment as described above, compare Figs. 5a, 6a, and 8. This shows that the microstructure after breakaway oxidation is not influenced by the presence of $\mathrm{H}_{2} \mathrm{O}$ in a major way, supporting the conclusion that the post-breakaway scale microstructure is governed by the inherent properties of the alloy and the $\mathrm{Fe}-$ Cr-Ni-O system as discussed above ([37, 38] and Fig. 9). 


\section{Conclusions}

- Breakdown of the thin protective scale occurred in $\mathrm{O}_{2}+\mathrm{H}_{2} \mathrm{O}+\mathrm{KCl}$, $\mathrm{O}_{2}+\mathrm{H}_{2} \mathrm{O}+\mathrm{SO}_{2}+\mathrm{KCl}, \mathrm{O}_{2}+\mathrm{K}_{2} \mathrm{CO}_{3}$ and $\mathrm{H}_{2}+\mathrm{H}_{2} \mathrm{O}+\mathrm{Ar}$ environment, but not in dry $\mathrm{O}_{2}$.

- In all environments the scale formed after breakaway oxidation consisted of two layers separated by the original metal/oxide interface, i.e. an inward growing spinel/reaction zone and an outward growing iron rich scale.

- The general features and microstructure of the scales formed after breakaway are not directly linked to the environment/breakaway mechanism. Instead they are general for the $\mathrm{FeCr}(\mathrm{Ni})$ system governed by:

- Different diffusivities of $\mathrm{Cr}^{3+}$ and $\mathrm{Fe}^{2+}$ in the spinel oxide.

- The appearance of a miscibility gap in the $\mathrm{FeCr}$ and $\mathrm{FeCrNi}$ spinel oxides.

- The equilibrium composition of the spinel (at low $\mathrm{pO}_{2} \mathrm{Ni}$ is not present in the spinel).

- The oxide precipitates in the internally oxidized metal consisted of iron chromium spinel oxide containing about $45 \% \mathrm{Cr}$ and $55 \% \mathrm{Fe}$ (cationic). The composition implies that the oxygen activity in the alloy where precipitation occurred was high in comparison to the alloy/oxide equilibrium. The formation of reaction zones may influence the properties/kinetics in the following ways:

- A network of interfaces between oxide/metal or oxide/oxide forms resulting in fast transport paths for ions.

- The remaining FeNi metal may be transformed into pores when acting as a source of ions for the outward growing oxide [5].

Acknowledgments This work was carried out within the High Temperature Corrosion Centre (HTC) at Chalmers University of Technology. The authors are grateful to Dr. Samuel Hallström and Dr. Lina Kjellqvist at Thermo-Calc Software AB for discussing the Thermo-Calc calculations.

Open Access This article is distributed under the terms of the Creative Commons Attribution 4.0 International License (http://creativecommons.org/licenses/by/4.0/), which permits unrestricted use, distribution, and reproduction in any medium, provided you give appropriate credit to the original author(s) and the source, provide a link to the Creative Commons license, and indicate if changes were made.

\section{References}


1. P. Kofstad, High Temperature Corrosion, (Elsevier, London, 1988).

2. N. Birks and H. Meier, Introduction to the High Temperature Oxidation of Metals, 2nd ed, (Cambridge University Press, London, 2006).

3. D. Young, High Temperature Oxidation and Corrosion of Metals, (Elsevier, New York, 2008).

4. B. Pujilaksono, T. Jonsson, H. Heidari, M. Halvarsson, J. E. Svensson and L. G. Johansson, Oxidation of Metals 75, 183 (2011).

5. T. Jonsson, B. Pujilaksono, H. Heidari, F. Liu, J. E. Svensson, M. Halvarsson and L. G. Johansson, Corrosion Science 75, 326 (2013).

6. F. Liu, J. E. Tang, T. Jonsson, S. Canovic, K. Segerdahl, J. E. Svensson and M. Halvarsson, Oxidation of Metals 66, 295 (2006).

7. T. Jonsson, F. Liu, S. Canivic, H. Asteman, J. E. Svensson, L. G. Johansson and M. Halvarsson, Journal of The Electrochemical Society 154, c603 (2007).

8. T. Jonsson, J. Froitzheim, J. Pettersson, J.-E. Svensson, L.-G. Johansson and M. Halvarsson, Oxidation of Metals 72, 213 (2009).

9. M. Halvarsson, J. E. Tang, H. Asteman, J.-E. Svensson and L.-G. Johansson, Corrosion Science 48, 2014 (2006).

10. A. N. Hansson, K. Pantleon, F. B. Grumsen and M. A. J. Somers, Oxidation of Metals 73, 289 (2010).

11. E. Essuman, G. H. Meier, J. Zurek, M. Hansel, L. Singheiser and W. J. Quadakkers, Scripta Materialia 57, 845 (2007).

12. N. Mu, K. Y. Jung, N. M. Yanar, G. H. Meier, F. S. Pettit and G. R. Holcomb, Oxidation of Metals 78, 221 (2012).

13. L. Liu, Z. G. Yang, C. Zhang, M. Ueda, K. Kawamura and T. Maruyama, Corrosion Science 60, 90 (2012).

14. D. J. Young, J. Zurek, L. Singheiser and W. J. Quadakkers, Corrosion Science 53, 2131 (2011).

15. G. H. Meier, K. Jung, N. Mu, N. M. Yanar, F. S. Pettit, J. P. Abellan, T. Olszewski, L. N. Hierro, W. J. Quadakkers and G. R. Holcomb, Oxidation of Metals 74, 319 (2010).

16. E. Essumana, G. H. Meierb, J. Zurekc, M. Hänseld, L. Singheisere and W. J. Quadakkers, Materials Science Forum 595-598, 699 (2008).

17. N. K. Othman, J. Q. Zhang and D. J. Young, Oxidation of Metals 73, 337 (2010).

18. H. Asteman, J.-E. Svensson, M. Norell and L.-G. Johansson, Oxidation of Metals 54, 11 (2000).

19. H. Asteman, J.-E. Svensson and L.-G. Johansson, Oxidation of Metals 57, 193 (2002).

20. S. Karlsson, T. Jonsson, J. Hall, J. E. Svensson and J. Liske, Energy \& Fuels 28, 3102 (2014).

21. J. Ehlers, D. J. Young, E. J. Smaardijk, A. K. Tyagi, H. J. Penkalla, L. Singheiser and W. J. Quadakkers, Corrosion Science 48, 3428 (2006).

22. G. Hultquist, B. Tveten and E. Hörnlund, Oxidation of Metals 54, 1 (2000).

23. Galerie, A., Y. Wouters, and M. Caillet, in 5th International Symposium on High Temperature Corrosion and Protection of Materials (Trans Tech Publications Ltd., Les Embiez, 2000).

24. J. Pettersson, H. Asteman, J.-E. Svensson and L.-G. Johansson, Oxidation of Metals 64, 23 (2005).

25. Hooshyar, H., J. Liske, and J. E. Svensson, in International symposium of High Temperature Oxidation and Corrosion (ISHOC) (2014).

26. L. A. Giannuzzi and F. A. Stevie, Introduction to Focused Ion Beams: Instrumentation, Theory, Techniques and Practice, (Springer, Berlin, 2005), p. 213.

27. E. V. Cappellen and J. C. Doukhan, Ultramicroscopy 53, 343 (1994).

28. J. O. Andersson, T. Helander, L. Höglund, P. F. Shi and B. Sundman, Calphad 26, 273 (2002).

29. B. Sundman, Journal of Phase Equilibria 12, 127 (1991).

30. Hooshyar, H., T. Jonsson, J. Hall, J.-E. Svensson, L.G. Johanssona, and J. Liske, Oxidation of Metals 1 (2015, submitted).

31. Hooshyar, H., M. Sattari, T. Jonsson, J. Liske, J.-E. Svensson, and L.G. Johansson, Oxidation of Metals (2015, submitted).

32. H. Asteman, J.-E. Svensson, M. Norell and L.-G. Johansson, Oxidition of Metals 54, 11 (2000).

33. B. Pujilaksono, T. Jonsson, H. Heidari, M. Halvarsson, J. E. Svensson and L. G. Johansson, Oxidation of Metals 75, 183 (2011).

34. N. K. Othman, N. Othman, J. Zhang and D. J. Young, Corrosion Science 51, 3039 (2009).

35. T. Jonsson, N. Folkeson, M. Halvarsson, J. E. Svensson and L. G. Johansson, Oxidation of Metals 81, 1 (2014).

36. J. Lehmusto, P. Yrjas, B. J. Skrifvars and M. Hupa, Fuel Processing Technology 104, 253 (2012).

37. J. Topfer, S. Aggarwal and R. Dieckmann, Solid State Ionics 81, 251 (1995). 
38. Van Orman, J. A. and K. L. Crispin, Diffusion in Oxides, in Diffusion in Minerals and Melts, eds. Y. X. Zhang and D. J. Cherniak (Mineralogical Society of America: Chantilly, 2010), p. 757.

39. T. Jonsson, B. Pujilaksono, S. Hallstrom, J. Agren, J. E. Svensson, L. G. Johansson and M. Halvarsson, Corrosion Science 51, 1914 (2009).

40. T. Jonsson, A. Järdnäs, J.-E. Svensson, L.-G. Johansson and M. Halvarsson, Oxidation of Metals 67, 193 (2007).

41. Jonsson, T., B. Pujilaksono, A. Fuchs, J.-E. Svensson, L.-G. Johansson, and H. Halvarsson, Materials Science Forum 595-598, 1005 (2008).

42. B. Pujilaksono, T. Jonsson, M. Halvarsson, J.-E. Svensson and L.-G. Johansson, Corrosion Science 52, 1560 (2010).

43. R. Egerton, Spectroscopy in the Electron Microscope, 3rd ed, (Springer, New York, 2011).

44. S. Hallstrom, L. Hoglund and J. Agren, Acta Materialia 59, 53 (2011).

45. R. Freer, Journal of Materials Science 15, 803 (1980). 